\title{
Preparation and characterization of toxic $\mathbf{A} \boldsymbol{\beta}$ aggregates for structural and functional studies in Alzheimer's disease research
}

\author{
Asad Jan ${ }^{1}$, Dean M Hartley² \& Hilal A Lashuel ${ }^{1}$ \\ ${ }^{1}$ Laboratory of Molecular Neurobiology and Neuroproteomics, Brain Mind Institute, Ecole Polytechnique Fédérale de Lausanne (EPFL), Lausanne, Switzerland. \\ ${ }^{2}$ Department of Neurological Sciences, Rush University Medical Center, Chicago, Illinois, USA. Correspondence should be addressed to H.A.L. (hilal.lashuel@epfl.ch) or \\ D.M.H. (dean_hartley@rush.edu).
}

Published online 3 June 2010; doi:10.1038/nprot.2010.72

\begin{abstract}
The amyloid cascade hypothesis, supported by strong evidence from genetics, pathology and studies using animal models, implicates amyloid- $\beta(A \beta)$ oligomerization and fibrillogenesis as central causative events in the pathogenesis of Alzheimer's disease (AD). Today, significant efforts in academia, biotechnology and the pharmaceutical industry are devoted to identifying the mechanisms by which the process of $A \beta$ aggregation contributes to neurodegeneration in $A D$ and to the identity of the toxic $A \beta$ species. In this paper, we describe methods and detailed protocols for reproducibly preparing $A \beta$ aggregates of defined size distribution and morphology, including monomers, protofibrils and fibrils, using size exclusion chromatography. In addition, we describe detailed biophysical procedures for elucidating the structural features, aggregation kinetics and toxic properties of the different $\mathbf{A} \boldsymbol{\beta}$ aggregation states, with special emphasis on protofibrillar intermediates. The information provided by this approach allows for consistent correlation between the properties of the aggregates and their toxicity toward primary neurons and/or cell lines. A better understanding of the molecular and structural basis of $A \beta$ aggregation and toxicity is crucial for the development of effective strategies aimed at prevention and/or treatment of AD. Furthermore, the identification of specific aggregation states, which correlate with neurodegeneration in $A D$, could lead to the development of diagnostic tools to detect and monitor disease progression. The procedures described can be performed in as little as 1 day, or may take longer, depending on the exact toxicity assays used.
\end{abstract}

\section{INTRODUCTION}

Alzheimer's disease (AD), the most common cause of senile dementia $^{1}$, is characterized pathologically by the formation of amyloid plaques and neurofibrillary tangles in the brain ${ }^{2}$. The principal components of amyloid plaques are the fibrillar aggregates of amyloid- $\beta$ (A $\beta$ ) peptides ${ }^{3}$ (39-43 amino acids), which are produced as a result of enzymatic proteolysis of amyloid precursor protein (APP) in neurons and other cells throughout life $\mathrm{e}^{4-6}$. Strong circumstantial evidence from genetics, pathology, biochemical studies and animal models led to the emergence of the $A \beta$ amyloid cascade hypothesis of $\mathrm{AD}^{7,8}$. This hypothesis stipulates a central role of $\mathrm{A} \beta$ production, oligomerization and/or fibrillogenesis (Fig. 1) in triggering a cascade of cellular and molecular events, which lead to the development of synaptic failure, synapse loss, neuronal loss and eventually dementia. Missing links between this cascade and AD pathogenesis include the identification of the mechanisms by which the process of $A \beta$ aggregation contributes to neurodegeneration and to the identity of the toxic $A \beta$ species. This knowledge is crucial for developing effective strategies to prevent and/or treat AD. Furthermore, the identification of specific aggregation states, which correlate with neurodegeneration in $\mathrm{AD}$, could lead to the development of diagnostic tools to detect and monitor disease progression. Such tools are crucial for evaluating the efficacy of therapies at different stages of $\mathrm{AD}$ pathogenesis.

In solution, $A \beta$ is unstructured, but acquires a $\beta$-sheet structure on aggregation and amyloid formation. Amyloid formation by $\mathrm{A} \beta$ follows a nucleation polymerization pathway that is characterized by an initial lag phase dominated by monomeric (M) species, followed by formation of low-molecularweight (LMW) oligomers (dimer, trimers and $<8$-mers) ${ }^{9,10}$.
A $\beta$-sheet-rich oligomeric 'nucleus' subsequently forms from these aggregates, which undergoes further growth to form higherorder aggregates of heterogeneous size and morphology distribution (Table 1). These $\beta$-sheet-rich oligomeric intermediates are collectively referred to as prefibrillar aggregates and disappear on fibril formation ${ }^{11-13}$. Some of the well-documented prefibrillar morphologies include protofibrils (curvilinear structures less than $200 \mathrm{~nm}$ in length and $4-6 \mathrm{~nm}$ in diameter $)^{12-14}, \mathrm{~A} \beta$-derived diffusible ligands (ADDLs; spherical aggregates 3-5 nm in diameter) ${ }^{15}$, $\mathrm{A} \beta$-annular assemblies (doughnut-like structures; outer diameter 8-12 $\mathrm{nm}$ and inner diameter 2-2.5 nm $)^{16-18}$ and LMW oligomers $^{17,19}$ (Table 1). Whether some of these species represent off- or on-pathway intermediates to amyloid fibril formation remains unknown. Some of the key distinguishing features of protofibrillar aggregates are that they (i) contain a mixture of different secondary structure elements with a predominance of $\beta$-sheet ${ }^{20}$; (ii) bind amyloid-specific dyes, such as Congo red and Thioflavin-T (ThT), although less strongly than mature fibrils ${ }^{20-22}$; and (iii) are less stable than mature amyloid fibrils and exist in equilibrium with monomeric $A \beta^{20,21,23}$. In the presence of monomeric $A \beta$, all these species convert to mature amyloid fibrils by monomer addition. Mature amyloid fibrils have been described as insoluble, $\beta$-sheet-rich structures that are more than $1 \mu \mathrm{m}$ long, 8-12 $\mathrm{nm}$ in diameter and composed of 2-6 protofilament subunits $^{24,25}$. In vitro, synthetic and recombinant forms of $\mathrm{A} \beta$ peptides have been shown to form aggregates and amyloid fibrils that are indistinguishable from the ones isolated from AD brain ${ }^{26-28}$. This suggests that the physiological process of amyloid formation can be recapitulated in vitro and highlights 
(1)

(2)

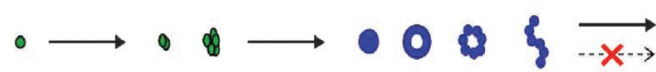

Figure 1 | A $\beta$ fibril formation pathway. (1) A $\beta$ monomers, under favorable conditions, can aggregate to form non-fibrillar and fibrillar aggregates. The non-fibrillar aggregates, based on their molecular size and/or morphology, can range from low-molecular-weight (LMW) oligomers $(n=2-8)(2)$ to highly ordered structures such as protofibrils and $A \beta$-derived diffusible ligands (ADDLs) (3). The non-fibrillar aggregates can be 'on pathway' (solid arrows) to fibril formation and disappear upon fibril formation (4), or 'off-pathway' (dashed arrows with a cross) species (that is, they do not convert into fibrils). Structures are not drawn to scale.

the relevance of in vitro studies for elucidating the molecular mechanism(s) of amyloid formation in vivo.

Several studies using familial $\mathrm{AD}$ (fAD) mutations in animal models and cell culture experiments strongly support the notion that early intermediates in the fibrillization process (i.e., oligomers, including protofibrils) are the primary toxic $\mathrm{A} \beta$ species and have a central role in $\mathrm{AD}$ pathogenesis. This hypothesis is supported by (i) the lack of a clear correlation between fibrillar amyloid burden in $\mathrm{AD}$ patients and cognitive impairment ${ }^{29,30}$, whereas such a correlation has been reported for the soluble pool of $\mathrm{A} \beta$ (monomers and oligomers including protofibrils) and $\mathrm{AD}$ severity ${ }^{31,32}$; (ii) the fact that autosomal dominant mutations in APP or its cleaving enzymes (presenilins), which favor increased production of $A \beta 42$ and/or accumulation of protofibrils, are associated with the development of $\mathrm{fAD}^{33-36}$; (iii) the indication that transgenic animals overexpressing fAD mutations in APP exhibit learning deficits and lower performance in memory tasks, compared with control animals, long before the appearance of amyloid plaques ${ }^{37,38}$; (iv) the fact that intracerebral administration of soluble $A \beta$ oligomers in live animals impairs cognitive performance and inhibits long-term potentiation (LTP), a cellular model of memory formation ${ }^{19}$, and induces widespread plaque pathology ${ }^{39}$; and (v) the observation that treating cultured neurons with $A \beta$ protofibrils results in impairment of ion channelss ${ }^{40,41}$, inhibition of LTP ${ }^{42}$, loss of synapses and cell deat $\mathrm{h}^{14}$. Finally, anti-A $\beta$ antibodies specifically targeting oligomers, including protofibrils, block neurotoxicity in cultured neuron ${ }^{43}$ and reverse behavioral deficits in mice ${ }^{44}$. Therefore, there is a vast academic, medical and commercial interest in identifying therapeutic agents that target specifically soluble $A \beta$ (monomers and oligomers, including protofibrils) and their impact on $\mathrm{AD}$ pathogenesis.

Studies using animal models of AD or using cultured neurons suggest that prefibrillar $A \beta$ aggregates, including LMW oligomers and protofibrils, exert their toxic effects by several potentially interrelated mechanisms, including pore formation $^{45}$, channel-like activity ${ }^{46}$, permeabilization of lipid bilayers ${ }^{47}$, inhibition of $\mathrm{K}^{+}$currents in cortical cultures ${ }^{40}$, disruption of neuronal glutamate uptake ${ }^{48}$, activation of apoptosis ${ }^{49}$, oxidative damage ${ }^{50}$ and degradation of postsynaptic density marker PSD-95 (ref. 51). A definitive correlation of any of these biological effects with the development and progression of $\mathrm{AD}$ is not straightforward and remains difficult to establish. A detailed molecular understanding of the process of amyloid formation, as well as the structural properties and dynamics of the various prefibrillar intermediates, is crucial for understanding the role of amyloid formation in $\mathrm{AD}$ pathogenesis. This requires access to experimental protocols that allow the preparation of sufficient quantities of well-characterized $A \beta$ aggregate states for structural and functional studies.
Various methods have been used to prepare different oligomeric and protofibrillar $A \beta$ species from synthetic $A \beta(s A \beta)$ peptides, and each method has its own advantages and disadvantages. Treatment of lyophilized $A \beta$ with strong acids and bases to disrupt preformed aggregates and enhance solubility ${ }^{52}$, filtration through LMW cutoff filters ${ }^{53}$, photo-induced crosslinking of unmodified protein ${ }^{17}$, density gradient centrifugation ${ }^{54}$ and size exclusion chromatography (SEC) $)^{13,14,17}$ have all been used to prepare soluble aggregates of $A \beta$ and yield preparations that vary in size and morphology distribution. SEC, in particular, offers several advantages: (i) a variety of column matrices with different separation capacities are readily available and can be used in isolation or in combination with other columns to obtain high-resolution separation and fractions containing $A \beta$ aggregates of defined size distribution; (ii) generally, the columns are equipped with filters at the top that allow for the removal of fibrillar (or insoluble) material from the injected sample, thus ensuring that the $A \beta$ fractions are free of fibrillar seeds; (iii) if SEC is coupled to a light-scattering detector, accurate determination of $A \beta$ aggregates' size distribution becomes possible ${ }^{20}$; (iv) in analytical mode, SEC is a valuable tool to monitor early events in amyloid formation and quantification of monomer and/or protofibril loss during the time course of fibril formation ${ }^{21}$; and (v) by choosing proper running conditions (i.e., buffer $\mathrm{pH}$ and contents), fractions are obtained in solution conditions suitable for biological systems, free of harmful or undesired substances (e.g., organic solvents and so on). SEC has also been successfully used to isolate $A \beta$ oligomers (such as dimers and trimers) and high-molecular-weight aggregates (including protofibrils and amorphous aggregates) from complex cell culture media ${ }^{55}$ or from postmortem AD brain extracts ${ }^{56}$.

Although it is one of the most commonly used methods for isolating and purifying $\mathrm{A} \beta$ oligomers ${ }^{13,21,23}$, SEC suffers from certain drawbacks that should be taken into consideration when using this technique: (i) some aggregates, because of their variable stability, may dissociate on interacting with column matrix and elute as LMW species $^{21}$; (ii) there may be a low resolution of separation if the sample is composed of a continuum of interconverting aggregates of related sizes; (iii) the samples are diluted in concentration after SEC fractionation and may not be suitable for use in certain experiments requiring high $\mathrm{A} \beta$ concentration; (iv) long duration of separation may allow interconversion and mask changes taking place within the time scale of minutes or less; (v) interactions with column matrices and separation may also be affected by factors other than size, such as aggregate conformation and tertiary structure; and (vi) nonspecific adsorption of hydrophobic peptides (such as $A \beta$ ) to the column matrix might result in a low yield of purified material.

\section{Previous results obtained using this protocol}

The early reports showing the appearance of protofibrils during the course of amyloid fibril formation in vitro $^{12}$ heightened the interest in obtaining these structures in purified form ${ }^{13}$. Using SEC, several groups showed that they can isolate protofibrillar aggregates, thus making it possible to elucidate their structural features and compare their toxicity with purified monomers or fibrils ${ }^{14,20}$. These studies have contributed significantly to (i) our current understanding of the mechanism of amyloid formation and its potential role in the pathogenesis of $\mathrm{AD}$; (ii) our knowledge of the physical and structural properties of different oligomeric and protofibrillar $\mathrm{A} \beta$ species; and (iii) the development of important research tools 
PROTOCOL

TABLE 1 | Glossary of $A \beta$ aggregation.

\begin{tabular}{|c|c|}
\hline Term & Description \\
\hline Amyloid & $\begin{array}{l}\text { Extracellular, insoluble proteinaceous deposits (plaques) that are composed primarily of fibrillar } \\
\text { aggregates comprising a single protein (A } \beta \text { in the case of AD-linked amyloid). Amyloid is defined by } \\
\text { its dye-binding properties: increased fluorescence and green birefringence with Thioflavin-T and } \\
\text { Congo red, respectively. In addition to the fibrillar protein, amyloid deposits contain other proteins, } \\
\text { glycosaminoglycans and proteoglycans }\end{array}$ \\
\hline Fibril & $\begin{array}{l}\text { Filamentous structure, consisting of } 2-6 \text { protofilaments, seen in cross-sections from disease-affected } \\
\text { tissue and also observed during aggregation of synthetic A } \beta \text { peptides in vitro. Mature fibrils are } \\
\text { characterized by: (i) cross- } \beta \text { X-ray fiber diffraction pattern; (ii) } \beta \text {-sheet rich CD and FTIR spectra; } \\
\text { (iii) binding to Congo red and Thioflavin-T and (iv) characteristic filamentous morphology ( } 8-12 \mathrm{~nm} \text { in } \\
\text { diameter, }>1 \mu \mathrm{m} \text { long) by AFM and TEM imaging (Figs. } 3 \mathbf{f} \text { and } 4 \mathrm{~h} \text { ). Depending on the solution and } \\
\text { incubation conditions, a given protein sequence can yield fibrils of diverse morphologies }\end{array}$ \\
\hline Protofilament & $\begin{array}{l}\text { Structural subunit of a mature fibril. Appear as twisted thread with a characteristic periodicity } \\
\text { and helical arrangement. (Note: different from protofibril (see below)) }\end{array}$ \\
\hline Oligomers & $\begin{array}{l}\text { The term 'oligomers' encompasses a wide range of species, ranging from low-molecular-weight (LMW) } \\
\text { species (including dimers, trimers and tetramers) to high-molecular-weight (HMW) oligomeric species } \\
\text { (such as spherical, chain-like and annular structures or longer structures (Fig. } 4 \mathrm{e}-\mathrm{g} \text { )). Fibrils are, by } \\
\text { definition, protein oligomers. Different types of oligomeric species have been described and are typically } \\
\text { distinguished by their composition, stability and molecular weight }\end{array}$ \\
\hline LMW oligomers & $\begin{array}{l}\text { Generally, LMW oligomer preparations contain a mixture of species that are less than 8-mers and are in } \\
\text { equilibrium with monomeric A } \beta \text {, as determined by denaturing SDS-PAGE gels or cross-linking studies. } \\
\text { These species are generally not detectable by standard TEM techniques. The smallest A } \beta \text { oligomer species } \\
\text { that could be visualized and its size determined by STEM was of } 42-80 \mathrm{kDa} \text {. Evidence for the LMW } \\
\text { oligomers has been primarily derived from denaturing SDS-PAGE electrophoresis experiments and cross- } \\
\text { linking studies. There is no evidence that these species accumulate in a stable form. Furthermore, the } \\
\text { possibility that these oligomers could be derived from HMW oligomers has not been ruled out }\end{array}$ \\
\hline $\begin{array}{l}\text { SDS-stable } \\
\text { LMW oligomers }\end{array}$ & $\begin{array}{l}\text { SDS-resistant LMW oligomers (<8-mers) have been prepared in vitro or isolated from natural sources } \\
\text { (cell cultures or brain tissues). LMW oligomers that are secreted from CH0 cells overexpressing wild-type } \\
\text { APP, or APP bearing fAD mutations, exhibit strong stability to SDS and chemical-induced dissociations, } \\
\text { whereas the majority of LMW oligomers generated in vitro by separation through a SEC column are SDS } \\
\text { sensitive, unless stabilized by chemical cross-linking. Naturally secreted LMW oligomers were shown to } \\
\text { inhibit LTP and impair cognitive performance when injected into rat brains at much lower concentration } \\
\text { than that used to observe toxicity with synthetic A } \beta \text {. However, despite extensive efforts by different } \\
\text { laboratories to establish the chemical identity and true stoichiometry of naturally formed SDS-stable } \\
\text { oligomers/aggregates by mass spectrometry, such data remain lacking and current size estimates are } \\
\text { solely based on their mobility in denaturing gels }\end{array}$ \\
\hline
\end{tabular}

High molecular Metastable A $\beta$ heterogeneous oligomers that can be visualized by TEM and AFM and range in size from weight $\sim 2 \mathrm{kDa}$ to $>1 \mathrm{mDa}$

- Protofibrils Metastable, heterogeneous, $\beta$-sheet rich prefibrillar structures that have been observed by AFM and TEM during amyloid fibril formation. Different protofibril preparations of $A \beta$ reveal heterogeneous mixtures of discrete $\beta$-sheet aggregates of different sizes (50-1,500 kDa) and morphologies (spherical (5-20 nm), annular structures and smooth, curvilinear structures ( $5 \mathrm{~nm}$ in diameter and $<200 \mathrm{~nm}$ in length)). TEM and AFM studies support a structural link between some of these different aggregates, but the mechanisms by which they form, the dynamics of their interconversion and their relationship with the amyloid fibrils remain poorly understood. Although protofibrils were initially thought to be on the linear pathway to fibrils, in its current usage, this term embraces all prefibrillar aggregates ( $\geq 4 \mathrm{~nm}$ ) that can be detected by EM and AFM. Protofibrils bind to Congo red and Thioflavin, although to a lesser extent than mature fibrils. Therefore, protofibrils here are kinetic intermediates, whereas protofilaments (see definition given above) represent the substructure of the amyloid fibril

-ADDLs Globular structures of 3-5 nm in diameter. Also referred to as globulomers. Initial reports, using mainly AFM and denaturing SDS-PAGE electrophoresis, suggested that these preparations contain primarily small oligomers 10-12-mers. However, subsequent solution characterization of the ADDL preparations showed that they consist of a heterogeneous population of $A \beta$ species, encompassing molecular sizes ranging from monomers to aggregates larger than $1 \mathrm{mDa}$, resembling the distribution observed for protofibrils

$12,13,15,16$ $18,20,21,93$

(continued) 
TABLE 1 | Glossary of A $\beta$ aggregation (continued).

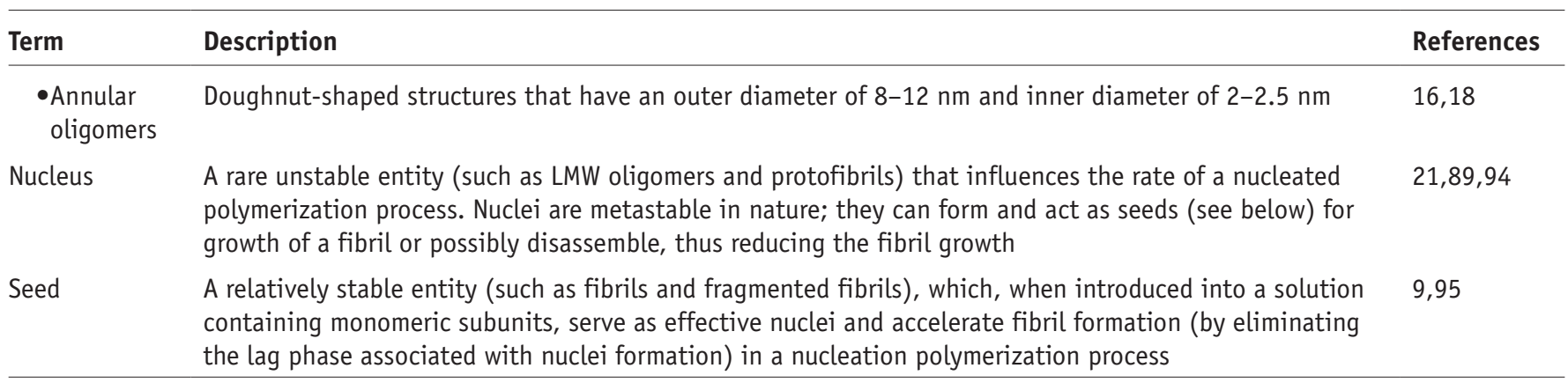

Abbreviations: $A \beta$, amyloid- $\beta ; A D$, Alzheimer's disease; ADDL, A 3 -derived diffusible ligand; $A F M$, atomic force microscopy; APP, amyloid precursor protein; $C D$, circular dichroism; $C H 0$, Chinese hamster ovary; EM, electron microscopy; FAD, familial AD; FTIR, Fourier transform infrared; SDS-PAGE, sodium dodecyl sulfate-polyacrylamide gel electrophoresis; STEM, scanning transmission electron microscopy;

TEM, transmission electron microscopy.

(such as conformational antibodies) and of novel amyloid-based diagnostic tools and therapeutic strategies.

Structural and mechanistic studies. The ability to purify protofibrils in sufficient quantities has facilitated biophysical and structural studies aimed at characterizing their structure and toxic properties. Biophysical studies, using multiple techniques, on SEC-purified A $\beta$ protofibrils revealed many important structural and physical features that distinguish these species from monomeric and fibrillar forms of $A \beta$. $A \beta$ protofibrils were shown to (i) bind amyloid-specific dyes such as Congo red and $\mathrm{ThT}^{18,20,21}$; (ii) be enriched with a $\beta$-sheet structure ${ }^{20}$; (iii) possess a core structure protected from solvent ${ }^{20,21,23}$; and (iv) exist in equilibrium with monomeric $A \beta^{20,21,23}$. Quasielastic light-scattering measurements revealed that SEC-purified A $\beta$ protofibrils contained aggregates with hydrodynamic radii $\left(R_{\mathrm{H}}\right)$ of $10-50 \mathrm{~nm}$, which correspond to lengths of $\sim 30-500 \mathrm{~nm}$ for noninteracting rods ${ }^{13}$. The heterogeneity of protofibrils was further elucidated by scanning transmission electron microscopy (TEM $)^{18}$ and sedimentation velocity measurements ${ }^{57}$. These studies revealed that protofibrils are a population of aggregates with molecular weight distribution ranging from $80 \mathrm{kDa}$ to $\sim 1 \mathrm{mDa}$ (ref. 23).

Previous studies have established the ratio of $A \beta 40$ to $A \beta 42$ as an important factor in determining the fibrillogenesis, toxicity and pathological distribution of $A \beta$ in vivo ${ }^{58-60}$. The ability to obtain monomeric and protofibril preparations of $A \beta 42$ and $A \beta 40$ by SEC allowed us to characterize the interactions between these two peptides at the levels of monomers, protofibrils and fibrils. This approach also enabled us to investigate how these interactions and changes in the relative ratio of $A \beta 42 / A \beta 40$ influence $A \beta$ oligomerization and fibrillogenesis in vitro. We showed that monomeric $A \beta 40$ is a potent inhibitor of monomer $A \beta 42$ amyloid formation at 1:1 ratio, whereas it inhibits fibrillization by $\mathrm{A} \beta 42$ protofibrils at substoichiometric amounts ${ }^{21}$. Furthermore, we found that $A \beta 42$ protofibrils seed the fibrillization of monomeric $\mathrm{A} \beta 42$ but not of monomeric $A \beta 40$. In contrast, fibrils composed of either $A \beta 42$ or $A \beta 40$ seeded the fibrillization of both $A \beta 42$ and $A \beta 40$ monomers ${ }^{21}$. Using these purified preparations, we were also able to show that monomeric $A \beta 42$ and $A \beta 40$ are constantly recycled and compete for binding to the ends of protofibrillar and fibrillar $A \beta$ aggregates ${ }^{21}$.

Finally, using the same monomer and protofibril preparations referred to above, we dissected the mechanism by which the heat shock protein (Hsp104) interferes with $A \beta$ oligomerization and fibrillogenesis. These studies revealed that $\mathrm{Hsp} 104$ inhibits $\mathrm{A} \beta$ fibrillization, targets different intermediates on the amyloid pathway and suppresses the seeding capacity of $A \beta 42$ protofibrils and fibrils by blocking their growth ${ }^{61}$.

Identifying the toxic $A \beta$ species and elucidating the mechanism of toxicity. A critical challenge in understanding the mechanism of $\mathrm{A} \beta$ toxicity, and in the subsequent design of intervention strategies, has been the correlation of a particular aggregate structure or size with biological effects, especially toxicity. Initially, fibrils were reported to be toxic, and inhibition of fibril formation or disruption of fibrils was considered to be a viable strategy for inhibiting $A \beta$ toxicity ${ }^{62-64}$. Subsequent studies, using SEC-purified protofibrils and monomers, showed that protofibrils exhibit stronger toxicity than monomeric and fibrillar $\mathrm{A} \beta^{14,20,21}$.

Together, these seminal studies showed that $\mathrm{A} \beta 40$ protofibrils consistently impaired neuronal metabolism ${ }^{20}$, instantly altered neuronal electrical activity and induced cell death ${ }^{14,21}$. SEC-purified monomeric $A \beta$, in contrast, had no effect on neuronal electrical activity $^{14}$ and required 3-5 d of incubation to induce quantifiable cell injury ${ }^{14}$. This observation suggested that some aggregation intermediates, formed during the incubation of monomeric $\mathrm{A} \beta$, were responsible for inducing toxicity. These findings were corroborated by studies in which cultured neurons were treated with monomers of highly amyloidogenic $A \beta$ sequences, $A \beta 42$ and A $\beta 40$-Arctic. The results showed that the treated neurons exhibited loss of processes within $7 \mathrm{~h}$ and cell death within 13-24 h of incubation with monomeric $A \beta 42$ and $A \beta 40-\mathrm{Arctic}^{65}$. Similarly, using SEC-isolated $A \beta 42$ protofibrils, we have shown that monomeric $A \beta 40$ inhibited $A \beta 42$ protofibril toxicity toward cultured neurons by altering their aggregation properties and inhibiting fibril formation. These observations reinforced the importance of an ongoing $A \beta$-nucleated polymerization as a critical factor for $A \beta$-induced toxicity ${ }^{21,66}$.

Size exclusion chromatography has also been used to characterize the relative toxicity of different $A \beta$ protofibril preparations and has improved our understanding of the nature of toxic species in such preparations. $\mathrm{ADDLs}$ are soluble $\mathrm{A} \beta$ aggregates that, by atomic force microscopy, appear as spherical structures of $3-5 \mathrm{~nm}$ in diameter ${ }^{15}$. SEC was used to fractionate ADDLs and different fractions were compared for binding to the neuronal surface ${ }^{67}$. Results showed that void volume ( $>70 \mathrm{kDa}$ ) fractions selectively bound to the cell surface and processes of neurons. No such binding was reported 
for fractions containing monomers to tetramers, suggesting that advanced oligomer states, protofibrils, are more likely to be the culprit toxic species in ADDL preparation ${ }^{67}$. Subsequent solution-state characterization of ADDL preparations revealed that they consist of a heterogeneous population of $A \beta$ species encompassing molecular sizes ranging from monomers to aggregates larger than $1 \mathrm{mDa}$, resembling the distribution observed for protofibrils.

In addition to $s \mathrm{~A} \beta$ oligomers, SEC has also been used to elucidate the nature of toxic $A \beta$ oligomers obtained from natural sources. The conditioned media of Chinese hamster ovary cells, stably expressing Val-717Phe fAD mutation in APP, contain monomeric and LMW oligomeric forms of $A \beta^{68}$. SEC was used to separate the monomers from oligomers and then fractions were used to assess the effects of both species on learning and memoryrelated tasks in rats. Intracerebroventricular injections into rats with fractions containing oligomers, but not monomers, were associated with significant errors in the behavioral performance of animals ${ }^{69}$. Transgenic (Tg 2576) mice, harboring the Swedish mutation in APP (APPSWE) linked to fAD, exhibit signs of memory deficits at the age of 6-14 months without accumulation of plaques or neuronal loss. Sodium dodecyl sulphate-polyacrylamide gel electrophoresis (SDS-PAGE) and SEC analysis of brain extracts from 6- to 14-month-old mice revealed that soluble multimers of $A \beta$, particularly a $56-\mathrm{kDa}$ species and to lesser extent a $40-\mathrm{kDa}$ species, correlated with the onset of memory deficit and remained stable during this time ${ }^{70}$. The $56-\mathrm{kDa}$ species $\left(A \beta^{\star} 56\right)$ was then purified by SEC and injected into the lateral ventricles of young healthy rats. Assessment of spatial memory task performance revealed that $A \beta^{\star} 56$ induced transient memory impairment in treated rats without affecting the learning of new tasks ${ }^{70}$. Thus, the use of SEC in the studies cited above allowed the investigators to selectively identify particular $A \beta$ oligomers (dimers and trimers or $A \beta^{\star} 56$ ) as the most likely cause of behavioral deficits observed in animal experiments.

Generation of novel tools and therapeutics. SEC-based methods, or information garnered from these methods, have also been useful for elucidating the mechanism of action of novel diagnostic and therapeutic approaches for AD. Immunizing rabbits with soluble oligomers of synthetic $A \beta$ mimics resulted in the generation of an antibody that selectively reacted with $A \beta$ oligomers in dot blot assays ${ }^{71}$. The antibody did not react with LMW or fibrillar preparations, suggesting conformation specificity for oligomers. SEC fractionation of $A \beta$ oligomers and subsequent dot blot assay with an oligomer-specific antibody showed that the smallest oligomer size detected by the antibody corresponded to a $40-\mathrm{kDa}$ protein ${ }^{71}$.
Interestingly, the antibody also showed binding to oligomeric preparations of other amyloidogenic sequences such as $\alpha$-synuclein and human insulin, suggesting a molecular conformation shared by oligomeric intermediates of these proteins. Most importantly, the antibody was not only able to discriminate between $\mathrm{AD}$-affected and normal brain but also distinguished thioflavin-S-positive (fibrillar) aggregates from non-thioflavin-S-binding (oligomeric) aggregates in $\mathrm{AD}$-affected brain ${ }^{71}$. Similarly, immunization of mice with ADDLs led to the generation of monoclonal antibodies that selectively reacted with oligomeric SEC fractions of ADDLs and not with monomeric fractions. Immunostaining of brain sections or dot blots on brain extracts by these antibodies showed their ability to discriminate $\mathrm{AD}$-affected from normal brain ${ }^{72}$.

\section{Experimental design}

The general procedure for isolating monomeric and protofibrillar $\mathrm{A} \beta$ fractions, and subsequent elucidation of their biophysical and biological properties, is outlined in Figure 2. To prepare monomeric $A \beta$ fractions, the lyophilized peptide is dissolved and disaggregated by guanidine hydrochloride treatment $t^{65,73}$, and then the solution is injected into a suitable SEC column to separate $\mathrm{A} \beta$ monomers from guanidine (Table 2).
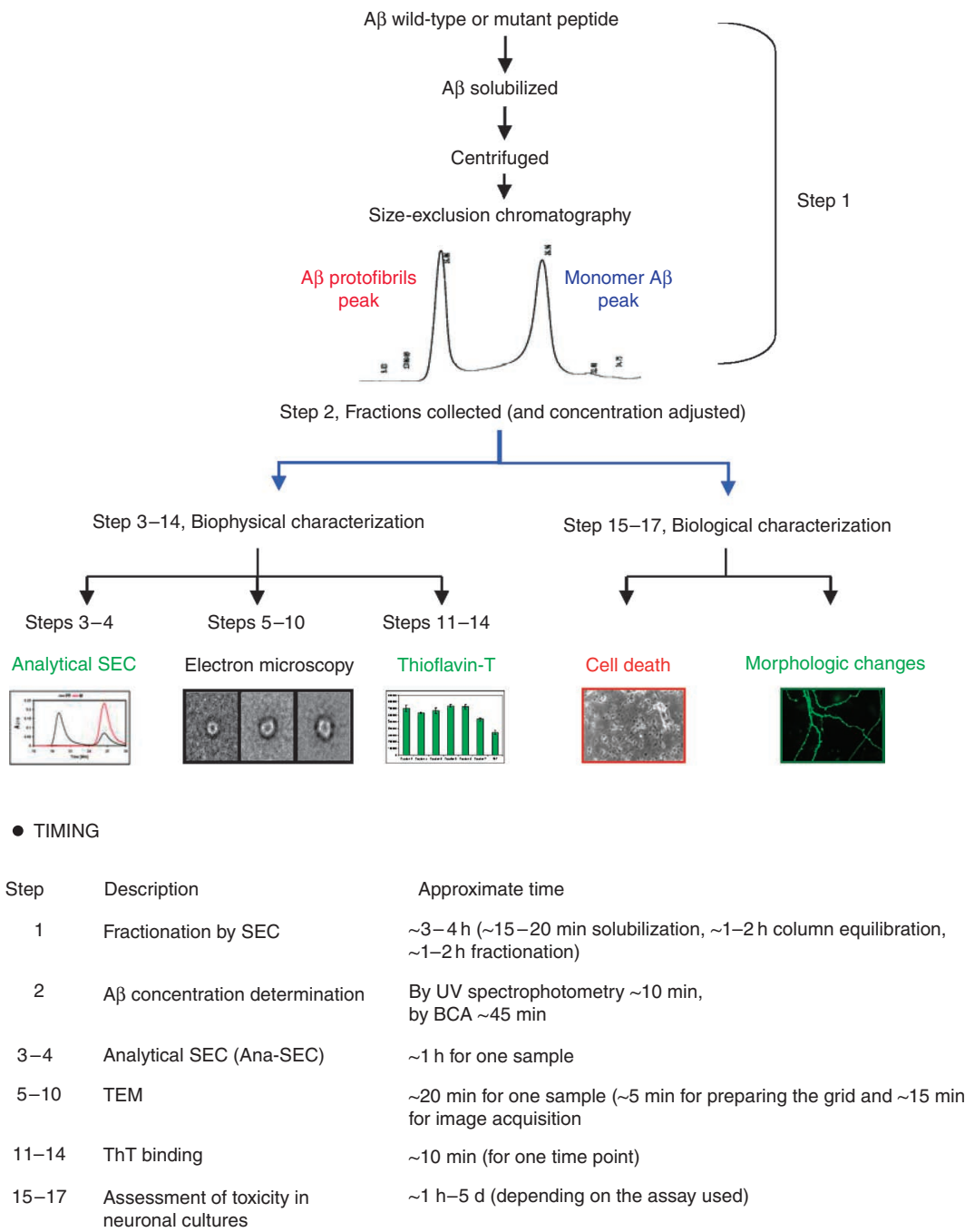

Figure 2 | Flow diagram illustrating steps and approximate timeline for A $\beta$ fractionation by SEC and subsequent biophysical and/or biological characterization. 
TABLE 2 | Fractionation range of SEC columns and A 342 fractions obtained after SEC.

\begin{tabular}{llccc}
\hline Serial no. & SEC column & $\begin{array}{c}\text { Separation range for } \\
\text { globular proteins (kDa) }\end{array}$ & $\begin{array}{c}\text { Protofibrillar } \\
\text { fractions (ml) }\end{array}$ & $\begin{array}{c}\text { Monomer } \\
\text { fractions (ml) }\end{array}$ \\
\hline 1 & Superdex 75 HR 10/30 & $3-70$ & $2(7-9)$ & $2(11-13)$ \\
2 & Superose 6 HR 10/30 & $5-5,000$ & $4-6(6-11)$ & $2(14-16)$ \\
\hline
\end{tabular}

Abbreviation: SEC, size exclusion chromatography.

This procedure yields fractions that are highly enriched ( $\geq 90 \%)$ in monomeric $A \beta$. Although these preparations are free of protofibrillar or fibrillar aggregates, the presence of unstable LMW oligomers (dimers, trimers, and so on) that are in rapid equilibrium with the major monomeric species has been suggested and cannot be ruled out. To prepare protofibrillar $A \beta$ fractions, the peptide is initially dissolved in $\mathrm{DMSO}^{57}$ and then aggregation is promoted under high-salt conditions. This leads to the generation of a solution enriched with $A \beta$ protofibrils and monomers. The different aggregation states and monomers are separated on a suitable SEC column (Table 2). Often, these aggregation parameters can be assessed and customized by monitoring the degree of monomeric versus protofibrillar $A \beta$ elution from the column. After a defined interval of incubation, if needed, the peptide solution is centrifuged to pellet out fibrils or insoluble material. The supernatant is then injected into a suitable SEC column capable of carrying out separation in a defined molecular size range, and $A \beta$ species are eluted from the column under isocratic conditions. To avoid unwanted $A \beta$ aggregation during the separation procedure, it is recommended that SEC fractionation be carried out using a chromatography system placed inside a cold $\left(4{ }^{\circ} \mathrm{C}\right)$ chamber. Alternatively, SEC can be carried out at room temperature (RT; $20-25^{\circ} \mathrm{C}$ ) provided that $\mathrm{A} \beta$ solutions are kept at $4{ }^{\circ} \mathrm{C}$ before injection and immediately transferred to $4{ }^{\circ} \mathrm{C}$ after eluting from the column. Fractions are then assessed for protein content and subsequently used for biophysical and/or biological studies. Biophysical studies may include further separation by SEC, characterization of the kinetics of fibril formation (such as ThT binding) and the structural and morphological properties of aggregates by imaging techniques such as electron microscopy and atomic force microscopy. For biological experiments, SEC monomeric or protofibrillar fractions are diluted by the addition of cell/tissue culture (TC) components needed for maintaining the osmolarity, $\mathrm{pH}$ and nutritive value of the media. Monomeric and protofibril fractions at high concentrations $(50-100-\mu \mathrm{M})$ are desired for these experiments. This can be achieved by scaling up the peptide preparation or using a modified or concentrated cell/TC media. Preparation of $A \beta$ fractions at higher concentrations, by scaling up the amount of injected peptide, is possible only up to a certain concentration: $2-3 \mathrm{mg} \mathrm{ml}^{-1}$ for slow aggregating $A \beta$ sequences (e.g., $A \beta 40$ ), but not for highly amyloidogenic $A \beta$ peptides such as $A \beta 42$ or the Arctic variant of both $\mathrm{A} \beta 40$ and $\mathrm{A} \beta 42$. At high concentrations of $>1-2 \mathrm{mg} \mathrm{ml}^{-1}$, the latter peptides start to fibrillize within minutes and precipitate, thus reducing the overall yield of monomers and protofibrils. Hence, a modified TC recipe for culturing primary neurons with concentrated components has been devised to minimize the dilution of $A \beta$ fractions (Table 3 ). With tissue components added,
TABLE 3 | Preparation of modified neurobasal components.

\begin{tabular}{|c|c|}
\hline Component & Composition \\
\hline Inorganic salts $(100 \times)$ & $m g$ per $10 \mathrm{ml} \mathrm{H}_{2} \mathrm{O}$ \\
\hline $\mathrm{CaCl}_{2} \cdot 2 \mathrm{H}_{2} \mathrm{O}$ & 264 \\
\hline $\mathrm{KCl}$ & 400 \\
\hline $\mathrm{MgCl}_{2} \cdot 6 \mathrm{H}_{2} \mathrm{O}$ & 162 \\
\hline $\mathrm{NaH}_{2} \mathrm{PO}_{4}$ & 108 \\
\hline Amino acids (100x) & $m g \operatorname{per} l \mathrm{H}_{2} \mathrm{O}$ \\
\hline Alanine & 20 \\
\hline Arginine $\mathrm{HCl}$ & 840 \\
\hline Asparagine $\cdot \mathrm{H}_{2} \mathrm{O}$ & 83 \\
\hline Cysteine & 121 \\
\hline Glutamine & 735 \\
\hline Glycine & 30 \\
\hline Histidine $\cdot \mathrm{HCl} \cdot \mathrm{H}_{2} \mathrm{O}$ & 420 \\
\hline Isoleucine & 1,050 \\
\hline Leucine & 1,050 \\
\hline Lysine $\mathrm{HCl}$ & 1,460 \\
\hline Methionine & 300 \\
\hline Phenylalanine & 660 \\
\hline Proline & 77.6 \\
\hline Serine & 420 \\
\hline Theronine & 950 \\
\hline Tryptophan & 160 \\
\hline Tyrosine & 720 \\
\hline Valine & 940 \\
\hline Vitamin solution $(100 \times)$ & $m g \operatorname{per} l \mathrm{H}_{2} \mathrm{O}$ \\
\hline $\mathrm{NaCl}$ & 8,500 \\
\hline D-Ca pantothenate & 100 \\
\hline Choline chloride & 100 \\
\hline Folic acid & 100 \\
\hline I-Inositol & 200 \\
\hline Nicotinamide & 100 \\
\hline Pyridoxal $\mathrm{HCl}$ & 100 \\
\hline Riboflavin & 10 \\
\hline Thiamine $\mathrm{HCl}$ & 100 \\
\hline
\end{tabular}


various neurotoxicity studies can be conducted. Lactate dehydrogenase (LDH) release or MTT (3-(4,5-dimethylthiazol-2-yl)-2, 5 -diphenyltetrazolium bromide) assays can be used to measure overt cell loss (Step 17A) or histological staining for subtle morphological changes using cytoskeletal markers (Step 17B) can also be carried out. Electrophysiological measurements on cultured cells or brain slices were shown to provide a highly sensitive and instantaneous readout of neuronal abnormalities caused by the addition of specific $A \beta$ aggregates, but require expensive equipment and specialized expertise, and will not be discussed in this paper ${ }^{14}$. Finally, biological activity can also be assessed in commercial cell lines of neuronal origin such as PC12 and SHSY5Y cells. In this case, modified commercial TC media (such as $10 \times$ Dulbecco's modified Eagle's medium) are commercially available and can be used to avoid further dilution of $A \beta$ fractions.

Although SEC has been used to obtain monomeric and protofibrillar forms of $A \beta$, the yield of the respective fractions may vary depending on the peptide sequence and the presence of preformed seeds in lyophilized peptide stock. It is known that $A \beta$ peptides from different manufacturers, or even different lots from the same source, may yield inconsistent aggregation and toxicity results $^{74}$. The approach outlined in this protocol ensures that the recovered peptide fractions are free of any fibrillar material and variability among different $A \beta$ preparations is minimized. Finally, to circumvent any potential problems associated with the use of sA $\beta$ peptides (such as impurities, racemization, salts or trace metals introduced during peptide synthesis and purification $^{52}$ ), many laboratories have developed methods for the expression of recombinant $\mathrm{A} \beta(\mathrm{rA} \beta)$ in $E$. coli $i^{75-77}$. $\mathrm{rA} \beta$ peptides have been shown to exhibit similar or higher toxicity compared with $s A \beta^{75,76}$. In addition to being free of any impurities associated with $s A \beta$, which might interfere with aggregation or toxicity, rA $\beta$ peptides also offer an inexpensive means of obtaining radioisotope-labeled $\mathrm{A} \beta$ for structural studies using $\mathrm{NMR}^{75,76}$.

The present protocol, principally based on the use of SEC, describes methods for generating monomeric, protofibrillar and fibrillar forms of $A \beta 40$ and $A \beta 42$, using $s A \beta$ and $\mathrm{rA} \beta$ peptides and $\mathrm{fAD}$ mutants (e.g., $A \beta 40$-Arctic and $A \beta 40$-Dutch) prepared with different counterions (trifluoroacetate (TFA) or sodium hydroxide) and obtained from different commercial suppliers and academic research groups.

\section{MATERIALS}

\section{REAGENTS}

- Human wild-type (wt) synthetic $A \beta 42$-wt, $A \beta 40$-wt and fAD mutants (A 440 -Arctic (E22G), A 340 -Dutch (E22Q) and A 340 -Flemish (A21G)). These were synthesized and purified as TFA salts by Dr. James I. Elliott, WM Keck Facility, Yale University, New Haven, CT, USA, as previously described ${ }^{78} \Delta$ CRITICAL Aliquot the lyophilized peptide in glass vials, seal with a tight wrapping of parafilm and store the aliquots at $-20^{\circ} \mathrm{C}$. Before use, bring the peptides to RT by leaving the vial in a dry place for 10-15 min. Do not remove the parafilm wrapping except just before weighing and/ or solubilization (see Step 1 of PROCEDURE). It is recommended to store the vials in a box containing a desiccant (EM Sciences, cat. no. 71225-00) for this purpose.

- DMSO (Sigma, cat. no. 41639) $\Delta$ CRITICAL DMSO is hygroscopic and should be stored in a dry place.

- Tris (hydroxymethyl)-aminomethane (Tris-base; Sigma, cat. no. T1503)

- Trizma hydrochloride solution (Tris-HCl, 1 M; Sigma, cat. no. T2663)

- Hydrochloric acid (32\% (wt/vol) Merck, cat. no. 1.00319.1000) ! CAUTION It is extremely corrosive and toxic and readily produces toxic vapors. Use a fume hood, face mask, eye protection and gloves while handling.

- Sodium hydroxide solution (NaOH, $1 \mathrm{~N}$; Sigma, cat. no. 59223C)

! CAUTION It is extremely corrosive and toxic. Use a fume hood, face mask, eye protection and gloves while handling.

- Guanidine hydrochloride (Gn-HCl; Sigma, cat. no. G4630) ! CAUTION It is toxic and an irritant.

- Uranyl acetate (UA; Electron Microscopy Sciences, cat. no. 22400)

! CAUTION It is a radioactive chemical, toxic if inhaled or ingested and it is categorized as a suspected carcinogen. Wear gloves, eye protection and face mask while handling.

- Thioflavin-T (ThT; Sigma, cat. no. T3516)

- Glycine (Sigma, cat. no. 50046)

- Bicinchoninic acid (BCA) protein assay kit (Pierce, cat. no. 23227)

- DMEM $(1 \times$, high glucose without glutamine and sodium pyruvate; Invitrogen, cat. no. 11960-051)

- Hank's buffered salt solution (HBSS; Invitrogen, cat. no. 14185052)

- (4-(2-Hydroxyethyl)-1-piperazineethanesulfonic acid) (HEPES, $1 \mathrm{M}$; Invitrogen, cat. no. 15630-080)

- PBS (GIBCO, cat. no. 10010-015)

- Sorensen's phosphate buffer (0.15 M; Electron Microscopy Sciences, cat. no. 11682-10)

- F-12 nutrient mixture (Invitrogen, cat. no. 11765-054)

- B-27 supplement (Invitrogen, cat. no. 10889-038)

- Neurobasal medium (Invitrogen, cat. no. 10888-022)
- FBS (GIBCO, cat. no. 10101145)

- Penicillin-streptomycin (Pen-strep, 100×; GIBCO, cat. no. 15140-122)

- Poly-L-lysine, 331 (MW 331 k; Sigma, cat. no. P-1524)

- Laminin (Sigma, cat. no. L2020)

- Trypsin-EDTA (Invitrogen, cat. no. 25200-056)

- L-Glutamine (200 mM; GIBCO, cat. no. 25030)

- Inorganic salts (100×; Table 4)

- Amino acids (100x; Table 4)

- Vitamin solution (100×; Table 4)

- Lactate dehydrogenase cytotoxicity assay kit (Cayman chemical, cat. no. 10008882). It contains $\mathrm{LDH}$ diaphorase, $\mathrm{NAD}^{+}(100 \times)$, lactic acid $(100 \times)$, LDH standard, cell-based assay buffer tablet, LDH (tetrazolium salt (INT) $(100 \times))$

- Mouse monoclonal microtubule-associated protein-2 antibody

(MAP-2; Sigma, cat. no. M2320)

- Rabbit polyclonal neurofilament-M (NF-M) antibody (Millipore, cat. no. AB1987)

- Alexa Fluor 488 goat anti-mouse IgG (Invitrogen, cat. no. A-11001)

- Alexa Fluor 594 donkey anti-rabbit IgG (Invitrogen, cat. no. A-21207)

- 4',6-Diamidino-2-phenylindole, dihydrochloride (DAPI; Invitrogen, cat. no. D1306)

- ProLong Gold antifade reagent with DAPI (Invitrogen, cat. no. P36931) EQUIPMENT

- Tabletop centrifuge (Eppendorf, model no. 5417R) with adjustable temperature and speed controls

- Vortex genie 2 (Scientific Industries, model no. G560E) or other suitable vortexing equipment

- ÄKTAexplorer fast protein liquid chromatography (FPLC; GE Healthcare) or any other chromatography system equipped with a UV detector and a fraction collector

- Carry 100-Bio UV spectrophotometer (Varian) or any other UV-VIS spectrophotometer

- Microcell (10-mm pathlength; Varian, part no. 6610010400) or appropriate microcell for UV-VIS spectrophotometry

- Size exclusion chromatography (SEC) column, Superdex 75 HR 10/30 (GE Healthcare, cat. no. 17-1047-01; 1 column volume $(\mathrm{CV})=24 \mathrm{ml}$ )

- SEC column, Superdex 75 pc 3.2/30 (GE Healthcare, cat. no. 17-0771-01; $1 \mathrm{CV}=2.4 \mathrm{ml}$ )

- SEC column, Superose 6 HR 10/30 (GE Healthcare, cat. no. 17-0537-01; $1 \mathrm{CV}=24 \mathrm{ml}$ )

- SEC column, Superose 6 pc 3.2/30 (GE Healthcare, cat. no. 17-0673-01; $1 \mathrm{CV}=2.4 \mathrm{ml})$ 
- Sample loop, PEEK (1 ml; GE Healthcare, cat. no. 18-1114-01)

- PEEK tubing (i.d. $0.75 \mathrm{~mm}$; GE Healthcare, cat. no. 8-1112-53)

- Standard 1.5-ml plastic micro test tube or equivalent (low protein binding) (Eppendorf 3810x; Eppendorf, cat. no. 0030 125.150)

- Sterile microtubes (Fisherbrand, cat. no. 05-669-27)

- HPLC separation module (2795) with PDA detector (Waters) for analytical SEC (Ana-SEC) or any other chromatography system for high-sensitivity measurements

- A Philips CM10 transmission electron microscope (TEM; Philips) equipped with a Morada CCD camera or other TEM setup with image acquisition equipment

- Formvar/carbon-coated TEM grids (Electron Microscopy Sciences, cat. no. FCF200-Cu-50)

- Grid storage box (Electron Microscopy Sciences, cat. no. 71140)

- High-precision ultrafine tweezers (Electron Microscopy Sciences,

cat. no. 78318-3X)

- Parafilm (Milian, cat. no. ARA-994)

- Cell culture plates (96-well; BD Falcon, cat. no. 353072)

- Cell culture plates (24-well; BD Falcon, cat. no. 353047)

- Plates, black (384-well; Nunc, cat. no. 262260)

- Glass coverslips (12-mm) or coverslips that use German-made glass (Carolina Biological Supplies, cat. no. BA-62-4734)

- Microdissection forceps (Carolina Biological Supplies, cat. no. 633009)

- HERAcell incubator (Thermo Scientific, model. no. 150) or any other appropriate cell culture incubator $\left(37^{\circ} \mathrm{C}, 5 \% \mathrm{CO}_{2}\right.$ and $100 \%$ humidity)

- Precision incubator (Memmert, model no. INB 400) or any other temperature-controlled incubator

- Fluorescence microplate reader (Analyst AD; Molecular Devices)

- Absorbance microplate reader (Safire 2; TECAN)

- Stericup-GP polyethersulfone (PES) filtration unit $(0.22 \mu \mathrm{m}, 500 \mathrm{ml}$; Millipore, cat. no. SCGPU05RE)

- UV/Vis photometer (Eppendorf, cat. no. 6132000.008)

- Microcuvette (Eppendorf, cat. no. 0030106.300)

- Synthetic A 342 (as TFA salt; Bachem, cat. no. H-1368)

- rA $\beta$ peptides (rPeptides, cat. no. A-1002-2 (for TFA salt) and cat. no. A-1165-2 (for $\mathrm{NaOH}$ salt))

- Syringe filter (PES) $(0.22 \mu \mathrm{m}$; TPP, cat. no. 99722); PVDF or cellulose filter media can also be used for filtering buffers and solutions

REAGENT SETUP

Running buffer for preparative and Ana-SEC Add $10 \mathrm{ml}$ of $1 \mathrm{M}$ Tris- $\mathrm{HCl}$ ( $\mathrm{pH}$ 7.4) to $990 \mathrm{ml}$ of ultrapure $\mathrm{H}_{2} \mathrm{O}$. Filter and degas the solution with a vacuum-driven Stericup-GP $0.22-\mu \mathrm{m}$ PES filtration unit. $\mathbf{C}$ CRITICAL Prepare fresh buffer each time. For most of the biophysical studies, Tris buffer can be used with the addition of $0-70 \mathrm{mM} \mathrm{NaCl}$. However, Tris is toxic to neurons, and thus HEPES is used for cell-based assays ( $70 \mathrm{mM} \mathrm{NaCl}+10 \mathrm{mM}$ HEPES ( $\mathrm{pH} 7.4)$ ). Guanidine hydrochloride solution $(6 \mathrm{M})$ Dissolve $5.8 \mathrm{~g}$ of guanidine hydrochloride (analytical grade) in $5 \mathrm{ml}$ of ultrapure $\mathrm{H}_{2} \mathrm{O}$ by continuous vortexing until a visibly clear solution is achieved. Bring the solution's final volume to $10 \mathrm{ml}$ and store at $4{ }^{\circ} \mathrm{C}$. $\Delta$ CRITICAL Bring the solution to RT before use by leaving the solution on a bench for $\sim 5-10 \mathrm{~min}$. Wear gloves while handling. - PAUSE POINT The solution can be stored at $4{ }^{\circ} \mathrm{C}$ for $2-3$ months. Presence of precipitates warrants immediate disposal.

Tris base solution (2 M; pH 7.6) Dissolve $2.2 \mathrm{~g}$ of Tris base in $10 \mathrm{ml}$ of ultrapure $\mathrm{H}_{2} \mathrm{O}$ and mix until a visibly clear solution is achieved. Bring the $\mathrm{pH}$ to 7.6 with dropwise addition of $32 \% \mathrm{HCl}$ and with continuous mixing. Filter the solution with a $0.22-\mu \mathrm{m}$ PES syringe filter. PAUSE POINT The solution can be stored at $4{ }^{\circ} \mathrm{C}$ for $2-3$ months. The presence of precipitates warrants immediate disposal.

UA solution (2\% (wt/vol)) Dissolve $200 \mathrm{mg}$ of UA in $10 \mathrm{ml}$ of ultrapure $\mathrm{H}_{2} \mathrm{O}$ and vortex until a particulate-free solution is achieved. Filter the solution using a syringe-driven $0.22-\mu \mathrm{m}$ PES filter and store at $4{ }^{\circ} \mathrm{C}$.

- PAUSE POINT The solution should be prepared as needed and can be stored at $4{ }^{\circ} \mathrm{C}$ for 1 month. $\triangle$ CRITICAL Dispose of the solution as per institutional regulations. Wear gloves while handling.

ThT solution $(100-\mu \mathrm{M})$ Dissolve $0.32 \mathrm{mg}$ of ThT in $10 \mathrm{ml}$ of ultrapure $\mathrm{H}_{2} \mathrm{O}$ until a particulate-free solution is achieved. Filter the solution using a $0.22-\mu \mathrm{m}$ PES syringe filter. PAUSE POINT Aliquot the volume needed for the day (Step 12) and store the rest at $4{ }^{\circ} \mathrm{C}$. The solution can be stored at $4{ }^{\circ} \mathrm{C}$ for 2-3 months. The presence of precipitates warrants immediate disposal.

$\Delta$ CRITICAL Protect from light by wrapping the tube in aluminum foil.
TABLE 4 | Ordering information of the components for modified Neurobasal media.

\begin{tabular}{|c|c|c|}
\hline Component & Supplier & Catalog no. \\
\hline \multicolumn{3}{|l|}{ Inorganic salts } \\
\hline $\mathrm{CaCl}_{2} \cdot 2 \mathrm{H}_{2} \mathrm{O}$ & VWR & EM-CX013-1 \\
\hline $\mathrm{KCl}$ & VWR & JT3040-1 \\
\hline $\mathrm{MgCl}_{2} \cdot 6 \mathrm{H}_{2} 0$ & VWR & JT2444-1 \\
\hline $\mathrm{NaH}_{2} \mathrm{PO}_{4^{\prime}}$ anhydrous & VWR & JT3821-1 \\
\hline \multicolumn{3}{|l|}{ Amino acids in acid } \\
\hline Isoleucine & Sigma-Aldrich & I7403 \\
\hline Leucine & Sigma-Aldrich & L8912 \\
\hline Phenylalanine & Sigma-Aldrich & P5482 \\
\hline Tryptophan & Sigma-Aldrich & T8941 \\
\hline Tyrosine & Sigma-Aldrich & T8566 \\
\hline \multicolumn{3}{|l|}{ Amino acids in $\mathrm{H}_{2} \mathrm{O}$} \\
\hline Alanine & Sigma-Aldrich & A7469 \\
\hline Arginine $\mathrm{HCl}$ & Sigma-Aldrich & A6969 \\
\hline Asparagine $\cdot \mathrm{H}_{2} \mathrm{O}$ & Sigma-Aldrich & A7094 \\
\hline Cysteine & Sigma-Aldrich & C7352 \\
\hline Glutamine & Sigma-Aldrich & G8540 \\
\hline Glycine & Sigma-Aldrich & G8790 \\
\hline Histidine $\cdot \mathrm{HCl} \cdot \mathrm{H}_{2} \mathrm{O}$ & Sigma-Aldrich & H5659 \\
\hline Lysine $\cdot \mathrm{HCl}$ & Sigma-Aldrich & L8662 \\
\hline Methionine & Sigma-Aldrich & M5308 \\
\hline Proline & Sigma-Aldrich & P5607 \\
\hline Serine & Sigma-Aldrich & S4311 \\
\hline Theronine & Sigma-Aldrich & T8441 \\
\hline Valine & Sigma-Aldrich & V0513 \\
\hline Vitamin solution & Invitrogen & 1087845 \\
\hline \multicolumn{3}{|l|}{$\mathrm{NaCl}$} \\
\hline \multicolumn{3}{|l|}{ D-Ca pantothenate } \\
\hline \multicolumn{3}{|l|}{ Choline chloride } \\
\hline \multicolumn{3}{|l|}{ Folic acid } \\
\hline \multicolumn{3}{|l|}{ I-Inositol } \\
\hline \multicolumn{3}{|l|}{ Nicotinamide } \\
\hline \multicolumn{3}{|l|}{ Pyridoxal HCl } \\
\hline \multicolumn{3}{|l|}{ Riboflavin } \\
\hline Thiamine $\mathrm{HCl}$ & & \\
\hline
\end{tabular}

Glycine- $\mathrm{NaOH}$ solution (500 mM; pH 8.5) Dissolve $376 \mathrm{mg}$ of glycine in $10 \mathrm{ml}$ of ultrapure $\mathrm{H}_{2} \mathrm{O}$ until clear. Bring the $\mathrm{pH}$ to 8.5 by adding $1 \mathrm{~N} \mathrm{NaOH}$ while continuously mixing. Filter the solution with a $0.22-\mu \mathrm{m}$ PES syringe filter and store at $4{ }^{\circ} \mathrm{C}$. PAUSE POINT Remove the volume needed for the day (Step 5), and store the rest at $4{ }^{\circ} \mathrm{C}$ for up to $2-3$ months. The presence of precipitates warrants immediate disposal.

EQUIPMENT SETUP

Equilibration of SEC columns Connect the appropriate SEC column (Table 2) to an ÄKTAexplorer FPLC or any other equivalent chromatographic 
system, equipped with a UV detector and a fraction collector. Equilibrate the column with $10 \mathrm{mM}$ Tris- $\mathrm{HCl}(\mathrm{pH} 7.4)$ at a flow rate of $0.5 \mathrm{ml} \mathrm{min}{ }^{-1}$.

- PAUSE POINT The columns should be equilibrated with at least two CVs or more ( $\sim 50 \mathrm{ml}$ for HR 10/30 columns) until a flat baseline UV signal is achieved. For carrying out $A \beta$ fractionation, it is highly recommended to use a chromatography system placed in a $4{ }^{\circ} \mathrm{C}$ chamber. Alternatively, $\mathrm{A} \beta$ fractionation can still be carried out at RT, provided fractions are immediately transferred to ice (within 5-10 min of eluting from the column).

$\Delta$ CRITICAL For toxicity studies, the column is equilibrated with $70 \mathrm{mM}$ $\mathrm{NaCl}+10 \mathrm{mM}$ HEPES ( $\mathrm{pH}$ 7.4). The amount of $\mathrm{NaCl}$ used can vary from 0 to $70 \mathrm{mM}$ as desired. Test the $\mathrm{pH}$ of the eluant to ensure that a $\mathrm{pH}$ between 7.2 and 7.6 is obtained. All $A \beta$ preparations and column solutions used for cell culture experiments should be processed to maximize sterility. For storage and sterilization, columns should always be completely washed with $20 \%$ ethanol; for cleaning and sterilizing, the columns should be washed with $0.5 \mathrm{M} \mathrm{NaOH}$ solution (refer to the column data sheets provided by the manufacturer, for cleaning procedures). The columns can be operated at a higher flow rate (up to $1 \mathrm{ml} \mathrm{min}^{-1}$ ), provided the maximum operational pressure, as recommended by the manufacturer, is not exceeded.
Equilibration of Superdex 75 or Superose 6 pc 3.2/30 columns for Ana-SEC Connect the Superdex 75 pc 3.2/30 or Superose 6 pc 3.2/30 column to the FPLC placed in a $4{ }^{\circ} \mathrm{C}$ chamber. Equilibrate the column with two CVs $(\sim 5 \mathrm{ml}$ for pc $3.2 / 30$ columns) of $10 \mathrm{mM}$ Tris- $\mathrm{HCl}$ ( $\mathrm{pH} 7.4)$ at a flow rate of $0.05 \mathrm{ml} \mathrm{min}{ }^{-1}$. $\Delta$ CRITICAL Set the high pressure limit to $2.4 \mathrm{MPa}$ (Superdex $75 \mathrm{pc} 3.2 / 30$ ) or $1.2 \mathrm{MPa}$ (Superose $6 \mathrm{pc} 3.2 / 30$ ) to avoid damaging the column matrix. Cleaning and storage should be carried out as recommended by the manufacturer. Flow rate can be increased up to $0.1 \mathrm{ml} \mathrm{min}{ }^{-1}$, provided the maximum operational pressure, as recommended by the manufacturer, is not exceeded.

Neuronal toxicity studies Obtain cortical neurons from E16 mouse embryos (Box 1). Add the cells in plating medium (Table 5) to poly-L-Lysine-coated glass coverslips or plastic 24-well plates (Box 2 ) at a density of $\sim 2.5 \times 10^{5}$ cells per $0.4 \mathrm{ml}$ per well. Place the plates in a cell culture incubator under conditions of high humidity, $37^{\circ} \mathrm{C}$ and $5 \% \mathrm{CO}_{2}$. On day 2 , fully replace the media with neuronal growth media (Table 5) and return the plates to the $37^{\circ} \mathrm{C}$ incubator. PAUSE POINT Healthy cells should start to develop processes within $24 \mathrm{~h}$ of plating and interconnectivity should be observed $2-3 \mathrm{~d}$ after plating.

\section{PROCEDURE}

1) Fractionation of $A \beta$ by SEC (Fig. 2) $\bigcirc$ TIMING $~ 3-4 h$

\section{(A) Obtaining the monomeric form of various $A \beta$ peptides, including $A \beta 40$ and $A \beta 42$}

(i) Dissolve $1 \mathrm{mg}$ of $A \beta$ in $1 \mathrm{ml}$ of $6 \mathrm{M}$ guanidine hydrochloride and mix until a visibly clear solution is achieved.

$\Delta$ CRITICAL STEP By careful visual inspection, ensure that no precipitates are present and almost all of the lyophilized peptide has been dissolved in the solvent.

PAUSE POINT The vial/tube with the peptide can be centrifuged $(3,000 \mathrm{~g}$ at RT for $1 \mathrm{~min})$ before solubilization to bring the lyophilized peptide to the bottom of the vial/tube and minimize peptide loss.

(ii) Centrifuge the solution $\left(16,000 \mathrm{~g}\right.$ for $10 \mathrm{~min}$ at $\left.4^{\circ} \mathrm{C}\right)$ in a tabletop centrifuge.

(iii) Carefully draw the supernatant into a 1-mL syringe for subsequent injection for SEC (see below). $\triangle$ CRITICAL STEP Avoid taking pelleted material into the syringe, as it will cause pressure problems if injected into the SEC column.

(iv) Inject the supernatant, obtained from Step $1 \mathrm{~A}$ (iii), into a Superdex 75 HR 10/30 SEC column, using a 1-ml sample loop. $\triangle$ CRITICAL STEP Ensure that the column is equilibrated with appropriate running buffer, as outlined in EQUIPMENT SETUP above.

(v) Fractionate $A \beta$ at a flow rate of $0.5 \mathrm{ml} \mathrm{min}{ }^{-1}$ with the individual fraction size being $1 \mathrm{ml}$.

$\triangle$ CRITICAL STEP Set upper operational pressure limit to $1.8 \mathrm{MPa}$. ? TROUBLESHOOTING

(vi) Collect and combine the two fractions under elution peak at $11-13 \mathrm{ml}(0.45-0.55 \mathrm{CV}$ of the Superdex $75 \mathrm{HR} 10 / 30$ column). The combined fractions represent monomeric $A \beta$.

$\triangle$ CRITICAL STEP Immediately transfer the fractions to ice or keep at $4^{\circ} \mathrm{C}$, but do not freeze or leave at RT (if SEC is carried out at RT).

(B) Obtaining protofibrillar A 342 (or A $\beta 40$-Arctic and A 340 -Dutch mutants)

(i) Dissolve $1 \mathrm{mg}$ of $A \beta$ in $50 \mu \mathrm{l}$ of $100 \%$ DMSO. Carefully mix with pipette to avoid introducing air bubbles.

$\triangle$ CRITICAL STEP By careful visual inspection, ensure that no precipitates are present and that all of the lyophilized peptide has been dissolved in the solvent. To avoid A $\beta$ fibrillization, do not spend more than 30-60 s on this step.

PAUSE POINT To ensure maximal peptide recovery, the peptide vial/tube can be centrifuged $(3,000 \mathrm{~g}$ at RT for $1 \mathrm{~min}$ ) before adding the DMSO, collecting all of the lyophilized peptide at the bottom of the vial/tube.

(ii) Add $800 \mu \mathrm{l}$ of ultrapure $\mathrm{H}_{2} \mathrm{O}$ and carefully mix with a pipette.

(iii) Immediately add $10 \mu \mathrm{l}$ of $2 \mathrm{M}$ Tris-base solution ( $\mathrm{pH} 7.6)$ and vortex briefly (2-5 s).

PAUSE POINT This procedure leads to the formation of a mixture of monomer and protofibrillar AB42 in solution; however, the amount of protofibrils formed varies from $50-80 \%$ depending on the batch of the peptide and solubilization efficiency. To maximize the amount of protofibrils, incubate the solution at RT for 1-5 min.

(iv) Carry out centrifugation and SEC fractionation as described in Steps $1 \mathrm{~A}(\mathrm{ii}-\mathrm{v})$ above.

- PAUSE POINT Aß protofibrils elute in the void volume ( 7-9 $\mathrm{ml}$ of elution volume for HR 10/30 columns) and monomeric fractions elute similarly as mentioned in Step $1 \mathrm{~A}(\mathrm{vi})$.

(v) Combine the two fractions under void volume elution peak (7-9 $\mathrm{ml}$ of elution volume) and label as protofibrils. Separately combine the two fractions under elution peak at $11-13 \mathrm{ml}(0.45-0.55 \mathrm{CV}$ of the Superdex 75 HR 10/30 column) and label as monomeric $A \beta$. 


\section{BOX 1 | DISSECTING CEREBRAL CORTEX NEURONS}

1. Purchase Swiss Webster, time-pregnant mice (Taconic or Charles River) E15-16.

PAUSE POINT This age is optimal for removing meninges, and neurons are predominately postmitotic. Younger and older animals are more difficult to dissect because of problems in removing meninges.

2. Prepare three 60-mm sterile Petri dishes with $3 \mathrm{ml}$ of ice-cold dissection medium (Table 2) and place on ice.

- PAUSE POINT Keeping the brain ice cold during dissection improves the recovery of healthy neurons and keeps the brain architecture intact, facilitating microdissection.

$\Delta$ CRITICAL STEP Prepare in tissue culture (TC) hood.

3. Prepare two 35-mm sterile Petri dishes with $1 \mathrm{ml}$ of dissection medium (Table 2) and place on ice.

$\Delta$ CRITICAL STEP Prepare in TC hood.

4. Mice are killed under the guidelines of the Institution's Animal Care Committee and according to local governmental regulations.

5. After killing the pregnant mouse, place the animal on a clean disposable dipper, ventral side up, and wet down the animal's fur with $70 \%$ ethanol.

6. Using a pair of sterile scissors and forceps, cut the abdominal skin along the midline and retract skin to the right and left side.

7. Rinse any fur from the abdominal muscles with $70 \%$ ethanol and use a second pair of sterile scissors to cut the abdominal muscles and peritoneum along the midline. Retract the abdominal walls to expose the uterus carrying the embryos, which will be readily observable.

8. Pull out the uterus after cutting the connective tissue and vasculature and transfer to a sterile $100-\mathrm{mm}$ Petri dish placed on ice. $\triangle$ CRITICAL STEP When picking out the uterus containing embryos, do not grab and puncture the intestines, which might pose a risk of infecting the embryos with bacteria.

PAUSE POINT The intact uterus can be removed in a chain-like manner containing all embryos (on an average 8-12 embryos in a Swiss Webster mouse). In the following steps, transfer brain tissue to successive sterile dishes to reduce the possibility of bacterial contamination.

9. Dissect out the individual embryos by cutting open the uterus and amniotic sacks.

10. Using scissors, cut the head off at the neck region directly into the prepared $60-\mathrm{mm}$ dish containing ice-cold dissection medium placed on ice.

11. Under a dissection microscope at $\times 2$ magnification, cut the skin and the developing cranium (membranous and not calcified at this stage) along the midline.

$\triangle$ CRITICAL STEP Do not cut into the underlying neocortical surfaces.

- PAUSE POINT Less distortion of the brain increases the success of the microdissection.

12. With the brain exposed, scoop out the brain using fine forceps starting at the olfactory bulbs and moving posteriorly.

PAUSE POINT A pair of forceps is used to disconnect the cranial nerves and lift the brain out as one moves posteriorly. The brain is removed intact and placed into the next clean $60-\mathrm{mm}$ dish containing ice-cold dissection medium. Repeat this process for each of the remaining brains.

13. Transfer one brain into a $35-\mathrm{mm}$ dish with ice-cold dissection medium and remove the meninges. The meninges (easily visible because of their vascularity) are removed as a continuous sheet by grabbing with the tips of the fine forceps and peeling over the front of the brain and then back toward the brainstem.

$\triangle$ CRITICAL STEP Removing the meninges is an important step to avoid fibroblast contamination of cultures.

14. Using forceps and starting at the fissure between the two hemispheres, roll out the medial part of one hemisphere to reveal the hippocampus.

PAUSE POINT The hippocampus is at the medial interface of the upper surface of the neocortex and appears as a rostral-caudal curved tubule.

15. Using fine forceps, cut along the neocortex-hippocampus interface and remove the hippocampus.

PAUSE POINT The hippocampus removed at this stage can be used to prepare hippocampal cultures.

16. With the hippocampus removed and the neocortex rolled a little further laterally, cut with the fine forceps at the underlying neocortex (light, lateral area)-striatum (dark, medial, striated structure) interface. Repeat this step for each side and place the two cortical hemispheres into new $35-\mathrm{mm}$ dishes with ice-cold dissection medium.

PAUSE POINT The process of isolating each cerebral cortex from each brain is continued and all hemispheres are combined.

17. Carefully remove as much of the dissection medium as possible and then add $1 \mathrm{ml}$ of Trypsin-EDTA, mince with forceps and incubate for $10 \mathrm{~min}$ at $37^{\circ} \mathrm{C}$ to activate Trypsin.

PAUSE POINT Trypsin is kept cold before addition to minimize self-inactivation. In addition, Trypsin is frozen as 1-ml aliquots, allowing only the amount needed to be thawed for each dissection.

$\Delta$ CRITICAL STEP The repeated freezing and thawing of Trypsin, especially at $37^{\circ} \mathrm{C}$, will continually reduce the effectiveness of this protease.

18. While trypsinizing tissue, narrow the opening of a sterile glass Pasteur pipette by flaming the tip.

$\triangle$ CRITICAL STEP Do not narrow it too much.

19. Slowly triturate the trypsin-containing cortices through the pipette until a homogenous suspension is achieved.

20. Transfer the triturated tissue (should be around $1 \mathrm{ml}$ ) to a sterile $15-\mathrm{ml}$ tube and add $1 \mathrm{ml}$ of plating medium containing serum to inhibit the trypsin. The tissue and medium solutions are mixed with the trituration pipette. 


\section{BOX 1 | CONTINUED}

21. Count the cells using a hemocytometer.

PAUSE POINT Cells can be incubated with trypan blue before counting to determine the ratio of live to dead cells. Trypan blue is excluded from viable cells.

22. Finally, dilute the cells for plating in the plating media (Table 2) at a density of $2.5 \times 10^{5}$ cells per $0.4 \mathrm{ml}$ per well, then add to poly-L-lysine-coated 24-well plates or poly-L-lysine + laminin-coated coverslips (Box 2). Place plated cells into an incubator at $37{ }^{\circ} \mathrm{C}$.

$\triangle$ CRITICAL STEP Immediately transfer the monomeric and protofibrillar fractions to ice or keep at $4{ }^{\circ} \mathrm{C}$, but do not freeze or leave at RT (if SEC is carried out at RT).

\section{(C) Obtaining protofibrillar $A \beta 40$}

(i) Dissolve $A \beta 40$ at a concentration of $1 \mathrm{mM}\left(4.3 \mathrm{mg} \mathrm{ml}^{-1}\right.$, based on the total weight of the peptide) in $1 \mathrm{mM} \mathrm{NaOH}$ plus sterile phenol red $\left(0.1 \mathrm{mg} \mathrm{ml}^{-1}\right.$ to monitor the $\mathrm{pH}$ of the solution). The final $\mathrm{pH}$ of this solution is $\sim 3$.

$\triangle$ CRITICAL STEP By careful visual inspection, ensure that no precipitates are present and that all of the lyophilized peptide has been dissolved in the solvent.

PAUSE POINT The vial/tube with the peptide can be centrifuged $(3,000 \mathrm{~g}$ at RT for $1 \mathrm{~min})$ before solubilization to bring the lyophilized peptide to the bottom of the vial/tube and minimize peptide loss.

(ii) Add $140-155 \mu \mathrm{l}$ of $10 \mathrm{mM} \mathrm{NaOH}$ per mg of peptide.

$\triangle$ CRITICAL STEP To minimize isoelectric precipitation of $A \beta$ ( $p I \sim 5.5)$, which can vary between manufacturers and specific lots, $10 \mathrm{mM} \mathrm{NaOH}$ is added to achieve a rapid transition to a pH of 7.0-7.5. This can be visualized by orange to red color change, when phenol red is used as the $\mathrm{pH}$ indicator.

PAUSE POINT Additional acid or base can be added to achieve the proper $\mathrm{pH}$.

(iii) Dilute the peptide with sterile water and then with 10x PBS to yield a final concentration of $500 \mu \mathrm{M}$ peptide in $1 \times$ PBS (70 mM NaCl, $1.35 \mathrm{mM} \mathrm{KCl}$ and $5 \mathrm{mM} \mathrm{NaH}{ }_{2} \mathrm{P0} 4 / \mathrm{Na}_{2} \mathrm{HPO} 4$ (pH $\left.~ 7.4\right)$ ).

(iv) Incubate the solution at RT for 2-3 d to generate protofibrils and monomers of $A \beta 40$.

- PAUSE POINT The progression of the aggregation can be checked periodically by injecting small amounts of the mixture to observe the monomer to protofibril ratio.

(v) Carry out centrifugation and SEC fractionation as described in Step $1 \mathrm{~A}(\mathrm{ii}-\mathrm{v})$ above.

(vi) Combine the two fractions under void volume elution peak ( 7-9 $\mathrm{ml}$ of elution volume for the HR 10/30 columns) and label as protofibrils. Separately combine the two fractions under elution peak at $11-13 \mathrm{ml}$ (0.45-0.55 CV of the Superdex 75 HR 10/30 column) and label as monomeric $A \beta$.

$\triangle$ CRITICAL STEP Immediately transfer the monomeric and protofibrillar fractions to ice or keep at $4^{\circ} \mathrm{C}$, but do not freeze or leave at RT (if SEC is carried out at RT).

(D) SEC for subfractionating protofibrils

(i) Centrifuge the $A \beta$ peptide solution $(16,000 \mathrm{~g}$ for 10 min at $4^{\circ} \mathrm{C}$ ) obtained from Step1B(iv) and inject the supernatant, using a 1-ml sample loop, into a Superose 6 HR 10/30 SEC column.

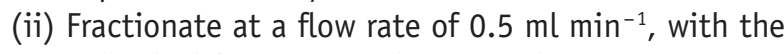
individual fraction size being $1 \mathrm{ml}$.

$\triangle$ CRITICAL STEP Set upper pressure limit to $1.5 \mathrm{MPa}$.

(iii) Collect four 1-ml fractions, corresponding to the elution volume of 6-11 ml, which contain the total protofibril peak, and do not combine. The monomer fractions (elution volume 14-16 ml) can be combined. $\triangle$ CRITICAL STEP Immediately transfer the fractions to ice or keep at $4^{\circ} \mathrm{C}$, but do not freeze or leave at RT (if SEC is carried out at RT).

PAUSE POINT Fractionation efficiency can also be increased by connecting two SEC columns in series (such as two Superose 6 HR 10/30 columns or a

TABLE 5 | Media for dissection and culture of neuronal cells.

\begin{tabular}{lc}
\hline Component & Volume (ml) \\
\hline Dissection medium & 500 \\
$5 \mathrm{ml}$ of 1 M HEPES & 5 \\
$5 \mathrm{ml}$ of 1 M glucose & 5 \\
$5 \mathrm{ml}$ of 1 M sucrose & 5 \\
$50 \mathrm{ml}$ of 10× Hank's salt & 50 \\
Cell culture-grade $\mathrm{H}_{2} 0$ & 435 \\
Plating medium & 500 \\
$1 \times$ DMEM (without glutamine) & 50 \\
FBS & 50 \\
F-12 & 50 \\
1 M HEPES & 10 \\
Glutamine & 5 \\
Pen-strep (100x) & 5 \\
H 0 & 330 \\
Growth medium for neuronal cultures & 100 \\
Neurobasal medium & 98 \\
B-27 & 2 \\
\hline
\end{tabular}

Abbreviations: HEPES, (4-(2-Hydroxyethyl)-1-piperazineethanesulfonic acid; Pen-Strep, Penicillin-streptomycin. 


\section{BOX 2 | COATING COVERSLIPS AND 24-WELL PLASTIC PLATES}

Neurons are plated onto either 24-well plastic plates for biochemical evaluation of cell viability or onto glass coverslips for histological observations.

1. Sterilize coverslips with $100 \%$ ethanol for a minimum of $2 \mathrm{~h}$ or overnight in a sealed sterile dish.

$\triangle$ CRITICAL STEP Do not use $70 \%$ ethanol, which will lead to coverslips being difficult to separate and potential breakage.

2. After sterilization, suction off ethanol and air-dry the coverslips in a sterile environment (e.g., in a TC hood).

3. Place one coverslip per well; a 12-mm coverslip fits into the well of a 24-well plate.

$\triangle$ CRITICAL STEP Low evaporation plates are necessary to minimize the liquid loss in the outside wells.

4. Prepare substrate solution to coat glass coverslips by combining poly-L-lysine (PLL) (MW 331K) + laminin solution. To obtain

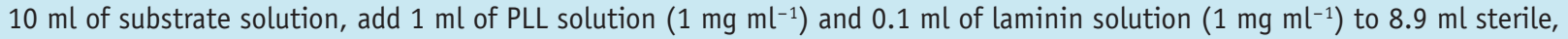

high-quality water.

PAUSE POINT Laminin is not needed if coating is carried onto plastic surfaces.

5. Add $300 \mu \mathrm{l}$ to each well containing a coverslip (requiring $7.2 \mathrm{ml}$ per 24 -well plate). Wrap plates in aluminum foil and incubate overnight at RT.

6. Next day, wash plates three times with sterile water and then air-dry in TC hood.

PAUSE POINT Plates that are not used immediately can be stored at $4{ }^{\circ} \mathrm{C}$, properly wrapped in aluminum foil.

TSK4000 SEC column connected in series to Superose 6 HR 10/30). However, in the latter case, to obtain A $\beta$ fractions at concentrations above $20 \mu \mathrm{M}, 1.5-2 \mathrm{mg} \mathrm{ml}^{-1}$ peptide should be solubilized for fractionation.

\section{Concentration determination}

2| The protein concentration of the fractions can be determined by different methods depending on the instrumentation available and desired accuracy. A $\beta$ concentration can be determined by measuring absorbance at $280 \mathrm{~nm}$ using a UV spectrophotometer or any of the commercially available protein assays (such as BCA assay). Both of these methods are readily available, but may contain marginal error. For measurements requiring high precision, amino-acid analysis (AAA) is recommended. The latter method requires sending the samples to a specialized facility, and requires a few hours/days to complete. If information regarding the absolute concentration of $A \beta$ fractions is critically needed, we recommend using one of the methods described below to determine the concentration for short-term reference, and sending some of the original solution for AAA. If the concentration determined by AAA is different from that determined by UV or BCA, the latter is then corrected accordingly. We have carried out a comparison of these methods for measuring $A \beta$ concentrations and the findings are summarized in

Box 3. Box 3 also contains some assay-related information for UV $A_{280} \mathrm{~nm}$ and $\mathrm{BCA}$, in the context of $\mathrm{A} \beta$ concentration estimations.

(A) Using UV spectrophotometry $\bigcirc$ TIMING 10 min

(i) Stabilize the light source of the spectrophotometer by turning on the lamp for $\sim 10-15$ min before its use. Obtain the UV absorbance of SEC running buffer (10-mM Tris-HCl ( $\mathrm{pH} 7.4)$ ), at wavelength $(\lambda) 280 \mathrm{~nm}\left(A_{280}\right)$, by placing $100 \mu \mathrm{l}$ of the buffer in a 10-mm-path-length cell. Set the reading of the spectrophotometer to zero using the unadulterated running buffer. Thereafter, obtain UV absorbance at $\lambda 280 \mathrm{~nm}$ for the different $A \beta$ fractions.

(ii) Calculate the molar concentration of $A \beta$ fractions by dividing $A_{280}$ values by the factor of 0.0015 (Box 4).

(iii) Adjust the concentration of individual fractions as appropriate for desired biophysical studies (10-20 $\mu \mathrm{M}$ for Steps 3, 5 and 11) or as appropriate for biological assays (Step 15) in SEC running buffer.

PAUSE POINT For neuronal toxicity studies, refer to Table 6 for sample preparation.

(B) Using BCA method $O$ TIMING 45 min

(i) For generation of a standard curve, dissolve $1 \mathrm{mg} \mathrm{ml}^{-1}$ of lyophilized $\mathrm{A} \beta 40(200 \mu \mathrm{M}$, based on dry weight) in high-purity $\mathrm{H}_{2} \mathrm{O}$ by continuous vortexing.

$\Delta$ CRITICAL STEP Aliquot $200 \mu \mathrm{l}$ of this stock $\mathrm{A} \beta$ solution per tube and store at $-20^{\circ} \mathrm{C}$ until needed. Use sterile tubes (Fisherbrand, cat. no. 05-669-27). Avoid repeated freezing and thawing of the peptide solution. Thaw the stock solution on ice.

PAUSE POINT Most of the SA $\beta$ is provided as peptide content of $~ 80 \%$ by dry weight. Check the peptide content from the $A \beta$ supplier and adjust accordingly.

(ii) Prepare the 'working reagent' (WR) provided in the BCA kit (follow manufacturer's instructions).

(iii) Using $A \beta 40$ stock $(200 \mu \mathrm{M})$, prepare $50 \mu \mathrm{l}$ of $A \beta 40$ protein at standard dilutions of $5,10,20,30,40,50,75,100,150$ and $200 \mu \mathrm{M}$ in high-purity $\mathrm{H}_{2} \mathrm{O}$ for generating a standard curve.

(iv) In a clear-bottomed 96 -well microplate, add $200 \mu$ l of WR to wells that will receive either unknown $A \beta$ samples or $A \beta$ standards.

(v) Add $25 \mu \mathrm{l}$ of each $A \beta$ standard to the appropriate well already containing WR.

$\triangle$ CRITICAL STEP Use $\mathrm{H}_{2} \mathrm{O}$ as blank control.

PAUSE POINT Each standard concentration should be tested with a minimum of duplicates. 


\section{BOX 3 | COMPARISON OF UV $A_{280 m^{\prime}}$ BICINCHONINIC ACID (BCA) ASSAY AND AMINO-ACID ANALYSIS (AAA) FOR DETERMINATION OF A $\beta$ CONCENTRATION}

We have outlined two commonly available methods of protein concentration determination, namely UV $A_{280}$ and BCA, in Step 2 of this protocol. However, the following points are worth mentioning in the context of $A \beta$ concentration estimations:

1. UV $A_{280}$ : The method relies on the molar absorbance coefficient for a particular protein (Box 4). Theoretically, the concentration of monomeric protein can be reliably assessed; however, the concentration of protofibrils contains a marginal error (as protofibrils do not have the same molar extinction coefficient as monomer). Therefore, another assay such as BCA can be used to increase the reliability of protofibril concentration determined by UV $A_{280}$. In addition, we have also observed that $\mathrm{A} \beta$ concentrations below $\leq 20 \mu \mathrm{M}$ are underestimated by the UV $A_{280}$ method than by BCA (see below). The most likely reason for this is the scarcity of aromatic residues in the A $\beta$ amino-acid sequence.

2. $B C A$ : The majority of commercial kits for determining protein concentrations (such as the PIERCE BCA kit) include BSA for generating a standard curve. The concentration of protein in unknown samples is determined using this standard curve. We found that a BSA standard curve results in $\sim 40-50 \%$ underestimation of $A \beta$ concentration in the fractions, compared with a standard curve based on $A \beta 40$ serial dilutions (Supplementary Fig. 4b). Moreover, there was close correlation between $A \beta$ concentration estimations by two assays, when we used a standard curve based on $A \beta 40$ serial dilutions. Therefore, we encourage the use $A \beta 40$ standard curve for $A \beta$ concentration estimations and not BSA. In contrast to $A \beta 42, A \beta 40$ is soluble in many aqueous media and less prone to aggregation. A 200- $\mu \mathrm{M}$ Aß40 stock solution can be used for 10 serial dilutions (5-200 $\mu \mathrm{M}$ ) with only $200 \mu \mathrm{l}$ of A 440 stock needed for one assay. Accordingly, repeated freeze and thaw cycles can be avoided by aliquoting the stock solution (200 $\mu \mathrm{l}$ per aliquot) and thawing it on ice. Freezing and thawing $A \beta$ may also introduce unwanted artifacts and interfere with the protein determination. To address this, we also carried out BCA assay on $A \beta 40$ solutions, which were either freshly prepared or aliquoted and frozen. Data show that both fresh and frozen $A \beta 40$ solutions yield comparable results by BCA (Supplementary Fig. 4c). However, repeated freezing and thawing of the stock $A \beta$ solution may introduce greater variablility and should be avoided.

3. Comparing $A A A, B C A$ and $U V_{280}$ : $A \beta$ concentration estimations by UV $\mathrm{A}_{280}$ or $B C A$ may contain a marginal error due to some limitations posed by the basic principles of each of these assays. AAA, however, is free of such limitations and provides a quantitative estimate of concentration and is more reliable. A comparative analysis of the three methods mentioned is summarized in Supplementary Figure 4a. Briefly, (i) BCA measurements were found to be $10-20 \%$ higher than UV measurements (A 340 standard curve was used for BCA); and (ii) UV $A_{280}$ measurements were $10 \%$ higher than AAA measurements. This applied to both monomeric and protofibrillar fractions.

(vi) Add $25 \mu \mathrm{l}$ of each AB sample of unknown protein concentration to the appropriate well already containing WR.

$\triangle$ CRITICAL STEP Use SEC running buffer as a blank control.

PAUSE POINT Each sample should be tested using a minimum of duplicates.

(vii) Cover the plate and incubate at $37^{\circ} \mathrm{C}$ for $30 \mathrm{~min}$.

(viii) Read the absorbance at $\lambda 562 \mathrm{~nm}$.

- PAUSE POINT If a microplate reader is not available, a suitable UV/Vis photometer (for example Eppendorf, cat. no. 6132000.008) can also be used. For this purpose, use a microcuvette (such as Eppendorf, cat. no. 0030106.300) to read each sample and proceed as outlined below.

(ix) Subtract $\mathrm{H}_{2} \mathrm{O}$ absorbance values from the standards and $\mathrm{SEC}$ running buffer absorbance from $A \beta$ samples.

— PAUSE POINT This step is required only if BCA is performed using a microplate reader.

$(x)$ Determine the concentration of $A \beta$ in each fraction $(\mu M)$ from the standard curve using Microsoft Excel or any other suitable software.

(xi) Adjust the concentration of individual fractions as appropriate for desired biophysical studies (e.g., 10-20 $\mu \mathrm{M}$ for Steps 3, 5 and 11) or as appropriate for biological assays (Step 15) in SEC running buffer.

PAUSE POINT For neuronal toxicity studies, refer to Table 6 for sample preparation.

\section{Analytical SEC $\bigcirc$ TIMING $\sim 1$ h for one sample}

3| Inject $50 \mu \mathrm{l}$ of each $A \beta$ fraction (protofibrils and monomer) into a Superdex 75 pc 3.2/30 SEC column connected to a Waters 2,795 separation module or any other chromatography system with high-sensitivity detectors.

\section{BOX 4 | DETERMINATION OF A $\beta$ CONCENTRATION BY UV A}

A $\beta$ concentration determination by UV spectrophotometry is based on the Beer-Lambert law: $c=A \div \varepsilon \times d$

In the equation above, ' $C$ ' denotes the molar concentration, ' $A$ ' is the UV absorbance at a particular wavelength, ' $\varepsilon$ ' is the molar extinction coefficient at that wavelength and ' $d$ ' is the path length of the UV cell. Keeping the path length as $1 \mathrm{~cm}(10 \mathrm{~mm})$ and the molar extinction coefficient at $280 \mathrm{~nm}\left(\varepsilon 280=1490 \mathrm{M}^{-1} \mathrm{~cm}^{-1}\right)^{86}$, the $A_{280}$ of $1 \mathrm{mg} \mathrm{ml}^{-1} \mathrm{~A} \beta$ is predicted to be 0.33 . In terms of molar concentration, this corresponds to $\sim 221 \mu \mathrm{M} \mathrm{A \beta 42} \mathrm{and} \sim 231 \mu \mathrm{M}$ A 340 . 
PAUSE POINT Protofibrillar fractions can also be analyzed by injection into a Superose 6 pc 3.2/30 column. The elution of protofibrils on a Superdex 75 pc 3.2/30 column provides a measure of protofibrillar content rather than size distribution. In contrast, on a Superose 6 pc 3.2/30, protofibrils elute as a broad peak in the void volume + included volume, thus allowing for analysis of heterogeneity and progression of aggregation.

4| Elute the fraction at a flow rate of $0.05 \mathrm{ml} \mathrm{min}^{-1}$ for 60 min.

$\triangle$ CRITICAL STEP Set the high pressure limit to $2.4 \mathrm{MPa}$ (Superdex 75 pc 3.2/30) or 1.2 MPa (Superose 6 3.2/30).

PAUSE POINT Although the PDA detector monitors sample elution at a range of wavelengths (200-400 nm), for analytical purposes, $A_{210-214} \mathrm{~nm}$ is adequate. Samples can also

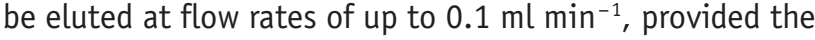
maximum pressure limit recommended by the manufacturer is not exceeded.

? TROUBLESHOOTING

\section{Morphological characterization by TEM $\bigcirc$ TIMING 20 min for one sample}

5| Deposit 2-10 $\mu$ l of a sample containing A $\beta$ on a formvar-coated TEM grid and let the sample droplet settle for $60 \mathrm{~s}$. $\triangle$ CRITICAL STEP Place A $\beta$ samples on TEM grids as soon as possible after fractionation to be able to assess the aggregation state of the starting material.

PAUSE POINT If the sample is $\geq 20 \mu \mathrm{M}$, deposit between 2 and $5 \mu \mathrm{l}$; for samples $<20 \mu \mathrm{M}$, deposit $5-10 \mu \mathrm{l}$. The grids can also be glow discharged, which improves subsequent sample deposition on the surface.

6| Remove excess solution by wicking the edge of the grid on a piece of blotting paper.

7| Deposit a $10-\mu \mathrm{l}$ drop of $2 \%$ UA on the grid and let it settle for $\sim 60 \mathrm{~s}$

8| Remove excess solution by wicking the edge of the grid on a piece of blotting paper.

9| Gently vacuum dry the grid from the edges.

$\triangle$ CRITICAL STEP Do not touch the grid with vacuum probe to avoid physical damage to the grid. Use the vacuum to produce an air current over the grid to evaporate the remaining liquid.

PAUSE POINT Grids can be placed in a storage box in a dry place. Storing in a desiccating chamber or box will help prevent moisture accumulation and sample degradation.

10| Acquire images on a CM10 TEM (or equivalent TEM), equipped with a CCD camera, operated at an acceleration voltage of $80-100 \mathrm{kV}$.

\section{? TROUBLESHOOTING}

\section{Assessment of fibril formation kinetics by ThT binding TIMING 10 min for one time point}

11| For fibrillization studies, aliquot 350-500 $\mu \mathrm{l}$ of each $A \beta$ fraction into two 1.5-ml sterile microtubes.

$\Delta$ CRITICAL STEP The sample volume should be $\geq 300 \mu \mathrm{l}$ in a $1.5 \mathrm{ml}$ polypropylene sterile microtube. Smaller volumes generate more errors during different aggregation experiments. Tubes larger than $1.5 \mathrm{ml}$ also pose a problem because of increased evaporation.

12| For ThT-binding measurements, mix $80 \mu \mathrm{l}$ of $10 \mu \mathrm{M} \mathrm{A} \beta$ fraction with $10 \mu \mathrm{l}$ of $100 \mu \mathrm{M}$ ThT and $10 \mu \mathrm{l}$ of $500 \mathrm{mM}$ glycine- $\mathrm{NaOH}$ (pH 8.5) in one well of a 384-well black plate.

$\triangle$ CRITICAL STEP Avoid generating air bubbles as they will interfere optically with fluorescence signal acquisition.

PAUSE POINT This step is described for a final concentration of $A \beta$ of $\sim 10 \mu \mathrm{M}$, a ThT:A $\beta$ ratio $\geq 1$ and a final glycine- $\mathrm{NaOH}$ concentration of $50 \mathrm{mM}$. The step can be modified to accommodate different concentrations of $A \beta$. For example, for a sample 
of $50-\mu \mathrm{M} \mathrm{A} \beta$, either dilute the sample with sample buffer to $10-\mu \mathrm{M}$ and proceed as above or use $70 \mathrm{mM}$ glycine- $\mathrm{NaOH}$ stock-solution $(20 \mu \mathrm{l} A \beta+70 \mu \mathrm{l}$ glycine- $\mathrm{NaOH}+10 \mu \mathrm{l} \mathrm{ThT}(100 \mu \mathrm{M}))$. Each sample should be assayed at least twice.

13 Acquire ThT fluorescence values using an Analyst AD fluorometer or a comparable fluorescence plate reader using an excitation wavelength of $\lambda 450 \mathrm{~nm}$ and an emission wavelength of $\lambda 485 \mathrm{~nm}$.

14| Close the lids of microtubes and incubate at $37{ }^{\circ} \mathrm{C}$ without agitation in a Precision incubator.

PAUSE POINT Acquire ThT fluorescence data for $96 \mathrm{~h}$ at $24 \mathrm{~h}$ intervals or as desired.

$\triangle$ CRITICAL STEP Briefly vortex the fractions before acquiring ThT fluorescence at each time point. ? TROUBLESHOOTING

\section{Assessment of toxicity in primary neuronal cultures $\bigcirc$ TIMING $\sim 1 \mathrm{~h}-5 \mathrm{~d}$ (depending on the assays used)}

15 On days 5-7 after cell plating, A $\beta$ fractions from SEC are mixed with components of a modified neurobasal media

(Table 6). Cultured neurons are exposed to various $A \beta$ aggregates by removing all the media and adding $0.4 \mathrm{ml}$ per well of the SEC fraction mixed with modified neurobasal media.

PAUSE POINT The eluate from the SEC will not sustain the viability of the cultured brain cells. Therefore, TC components need to be mixed with SEC fractions to correct sodium and potassium levels, provide energy and provide the correct $\mathrm{pH}$. Standard TC medium can be purchased, but SEC fractions might be low in A $\beta$ concentration, thus necessitating minimal further dilution of the SEC fraction by TC media. To accommodate this, modified neurobasal media are used to add TC components in minimal volumes (Table 3). Neurobasal medium was developed to specifically support neurons ${ }^{79}$. Using this formulation, TC components can be varied for experimental purposes. The TC components should be added to SEC fractions shortly before application to cells.

16| Remove media from neuronal cultures and replace with $A \beta$ fractions containing TC components and place the cells back in a $37^{\circ} \mathrm{C}$ incubator with $5 \% \mathrm{CO}_{2}$.

17| After $1 \mathrm{~h}$ to $5 \mathrm{~d}$, assess the effects of A $\beta$ treatment on neurons using biochemical methods such as LDH release assay and/or immunocytochemistry methods. LDH is a cytosolic enzyme that is primarily released on loss of integrity of the cell membrane and is a reliable indicator of cell death. The LDH release is proportional to the number of dead cells that can be measured in the culture medium. Alternatively, neurons plated on glass coverslips can be fixed and stained with antibodies to detect changes in neuronal architecture. The LDH release assay cannot detect cell loss, nor can it detect minor structural changes that may have important repercussions for the function of the neuron. Loss of synaptic connections would render a neuron as dysfunctional as neuronal death. The antibodies used here can also distinguish between changes in the dendritic (MAP2) versus axonal (NF-M) compartments.

(A) LDH release assay to determine cell death

(i) Prepare $100 \mathrm{ml}$ of buffer by adding one buffer tablet to $100 \mathrm{ml}$ of distilled water.

(ii) Prepare LDH diaphorase solution by adding $150 \mu \mathrm{l}$ of buffer and placing it on ice.

$\Delta$ CRITICAL STEP Extra solution can be frozen, but aliquoted to go through only one freeze-thaw cycle.

(iii) Prepare LDH reaction solutions by adding $100 \mu \mathrm{l}$ of the following four components to $9.6 \mathrm{ml}$ of buffer.

(a) LDH diaphorase (see Step 17A(ii))

(b) NAD $100 \times$ (provided in the kit)

(c) Lactic acid $100 \times$ (provided in the kit)

(d) INT 100x (tetrazolium salt) (provided in the kit)

(iv) Prepare the LDH standard by diluting the vial included in the kit with $1.8 \mathrm{ml}$ of buffer and placing immediately on ice. $\triangle$ CRITICAL STEP The LDH standard is not stable and the remaining solution should be stored at $-80^{\circ} \mathrm{C}$. The enzyme should only go through one freeze-thaw cycle.

(v) Dilute LDH standard in the ratio 1:20, 1:40, 1:80, 1:160 and 1:320, thus giving a standard curve of 10, 5, 2.5, 1.25 and $0.75 \mathrm{mU} \mathrm{ml}^{-1}$, respectively.

PAUSE POINT $1 \mathrm{U}$ of standard converts $1 \mu \mathrm{mol}$ of substrate per min.

(vi) Set up a standard curve in a 96-well plate by adding $100 \mu \mathrm{l}$ of standard to two or three wells for each concentration. Include a zero concentration by adding $100 \mu \mathrm{l}$ of the buffer prepared in the first well.

$\triangle$ CRITICAL STEP If serum is used in an experiment, it will contain LDH and could interfere with the assay.

(vii) Remove $100 \mu \mathrm{l}$ of the medium from the experimental wells and transfer to the plate containing standards.

(viii) Using the reaction solution prepared in Step 17A(iii), add $100 \mu \mathrm{l}$ to each of the standard and experimental wells.

(ix) Shake for $30 \mathrm{~min}$ at RT. Using a 96-well microplate reader (TECAN safire 2 or any other suitable microplate reader), measure absorbance at $\lambda 490 \mathrm{~nm}$. A standard curve of the $\mathrm{LDH}$ activity versus absorbance can be generated. The absorbance of the experimental sample can be used to determine LDH activity. 
PAUSE POINT The standard curve should be linear in the range of standards and the experimental samples should fall into this range. If not, higher samples must be diluted to bring them into the linear range of the standard curve.

PAUSE POINT The assay is based on Cayman Chemical Company's LDH assay and is outlined for measuring all wells in a 96-well plate. The assay for all standards and samples should be carried out either in duplicate or in triplicate. If more than one plate is needed, it is recommended to add standards to all plates that are being used.

\section{(B) Immunocytochemical staining of neurons}

(i) Fix cells in 4\% paraformaldehyde in $0.15 \mathrm{M} \mathrm{PO}_{4}$ (Sorenson's phosphate buffer plus $0.1 \%$ sodium azide) for $20 \mathrm{~min}$. I CAUTION Paraformaldehyde is toxic.

(ii) Wash cells three times for 5 min each with phosphate buffer.

(iii) Block the neurons with $10 \% \mathrm{FBS}+0.3 \%$ Triton $\mathrm{X}-100$ in $0.15 \mathrm{M} \mathrm{PO}_{4}$ for $1 \mathrm{~h}$ at RT.

(iv) Wash three times for 5 min each with phosphate buffer.

(v) Dilute both primary antibodies in the ratio $1: 500$ in $0.15 \mathrm{M} \mathrm{PO}_{4^{\prime}}$ apply to cells and incubate for $1 \mathrm{~h}$ at $\mathrm{RT}$. The MAP2 and NF-M antibodies can be incubated together, as one is a monoclonal (raised in mouse) and the other is a polyclonal antibody (raised in rabbit).

(vi) Wash three times for 5 min with phosphate buffer.

(vii) Dilute fluorescent secondary antibodies (Alexa Fluor 488 goat anti-mouse IgG and Alexa Fluor 594 donkey anti-rabbit $\mathrm{IgG})$ in $0.15 \mathrm{M} \mathrm{PO}_{4}$. Apply them onto the cells and incubate for $1 \mathrm{~h}$ at RT.

$\Delta$ CRITICAL STEP To avoid photobleaching the dye, cells should be kept in the dark during incubation and after washing.

(viii) Mount coverslips on slides with ProLong Gold mounting medium containing antifade reagent and the nuclei stain, DAPI.

- PAUSE POINT Antifade reagent helps suppress photobleaching. Coverslips are allowed to dry overnight, whereas plates can be assayed directly.

- PAUSE POINT Cultures can be visually monitored to determine when the experiment should be stopped depending on the response(s) of interest (for example, neuronal changes versus cell death). Small volumes of the medium can be tested from living cultures to determine whether cell death is occurring (such as by the release of LDH (Step 17A)). If the morphological changes in neurons are important, the entire medium at that time point is collected and the neurons are immediately fixed and stained (Step 17B). Morphological changes can be seen using the A 340 -Arctic peptide as early as $5 \mathrm{~h}$, whereas $A \beta 40$ wt peptide-induced cell loss could require 3-5 d.

\section{? TROUBLESHOOTING}

Troubleshooting advice can be found in Table 7.

TABLE 7 | Troubleshooting table.

\begin{tabular}{|c|c|c|c|}
\hline Step & Problem & Possible reason & Solution \\
\hline \multirow[t]{5}{*}{1,3 and 4} & \multirow[t]{5}{*}{ High column pressure } & 1. Precipitates or particulate matter & $\begin{array}{l}\text { 1. Ensure adequate peptide solubility and } \\
\text { proper centrifugation to remove precipitates }\end{array}$ \\
\hline & & $\begin{array}{l}\text { 2. Column not properly equilibrated and } \\
\text { contains traces of ethanol or other buffer } \\
\text { with high viscosity }\end{array}$ & $\begin{array}{l}\text { 2. Ensure proper column equilibration } \\
(2-3 \mathrm{CV})\end{array}$ \\
\hline & & $\begin{array}{l}\text { 3. A } \beta \text {, or other hydrophobic peptides, } \\
\text { sticking to the column from previous runs }\end{array}$ & 3. Try extensive cleaning with $0.5 \mathrm{M} \mathrm{NaOH}$ \\
\hline & & $\begin{array}{l}\text { 4. Very long }(>10 \mathrm{~cm}) \text { or narrow diameter } \\
\text { PEEK tubing }\end{array}$ & $\begin{array}{l}\text { 4. Use tubing of minimal length and } 0.75 \mathrm{~mm} \\
\text { internal diameter }\end{array}$ \\
\hline & & 5. Column matrix is degenerating & $\begin{array}{l}\text { 5. Use new columns or try extensive cleaning } \\
\text { with } 0.5 \mathrm{M} \mathrm{NaOH}\end{array}$ \\
\hline $5-10$ & $\begin{array}{l}\text { Clustering of } A \beta \text { aggregates } \\
\text { on TEM grid }\end{array}$ & $\begin{array}{l}\text { Decreased hydrophilicity of carbon coating; } \\
\text { contamination with organic molecules etc. }\end{array}$ & $\begin{array}{l}\text { The TEM grids should be treated with glow } \\
\text { discharge before sample application }\end{array}$ \\
\hline \multirow[t]{3}{*}{$11-14$} & \multirow[t]{3}{*}{$\begin{array}{l}\text { ThT values become stationary } \\
\text { or decrease after initial rise }{ }^{\text {a }}\end{array}$} & $\begin{array}{l}\text { 1. Lower than critical } A \beta \text { concentration for } \\
\text { fibrillization }\end{array}$ & $\begin{array}{l}\text { 1. Check the } A \beta \text { concentration in samples } \\
\text { and use a higher concentration, if too low, } \\
\text { than that initially estimated }\end{array}$ \\
\hline & & $\begin{array}{l}\text { 2. Increased evaporation from the tube, } \\
\text { or low sample volume }\end{array}$ & $\begin{array}{l}\text { 2. Use a sample volume that leaves at least } \\
100-200 \mu \mathrm{l} \text { at the end of measurement }\end{array}$ \\
\hline & & $\begin{array}{l}\text { 3. Clustering of fibrils, reducing the access } \\
\text { of ThT to binding sites on fibrils }\end{array}$ & $\begin{array}{l}\text { 3. Vortex and/or sonicate in a water bath } \\
\text { briefly }(\sim 30 \mathrm{~s}) \text { before the assay }\end{array}$ \\
\hline
\end{tabular}

Abbreviations: $A \beta$, amyloid- $\beta$; $C V$, column volume; TEM, TEM, transmission electron microscopy; ThT, Thioflavin-T.

aThis can also be a normal phenomenon, if free $A \beta$ monomers are scarce and no further elongation of fibrils is taking place. 


\section{TIMING}

Step 1, Fractionation of A $\beta$ by SEC: $\sim 3-4 \mathrm{~h}(\sim 1-2 \mathrm{~h}$ column equilibration, $\sim 15$ min solubilization and centrifugation and $\sim 1-2 \mathrm{~h}$ fractionation)

Step 2, A $\beta$ concentration determination: $\sim 10$ min by UV spectrophotometry and $\sim 45$ min by BCA

Steps 3 and 4, Analytical SEC: $\sim 1$ h for one sample

Steps 5-10, TEM: $20 \mathrm{~min}$ for one sample ( $5 \mathrm{~min}$ for preparing the grid and $\sim 15 \mathrm{~min}$ for image acquisition)

Steps 11-14, ThT binding: 10 min for one time point

Steps 15-17, Assessment of toxicity in neuronal cultures: $1 \mathrm{~h}-5 \mathrm{~d}$ (depending on the assays used)

\section{ANTICIPATED RESULTS}

This paper describes a step-by-step method, principally based on SEC, for generating preparations of A $\beta$ monomers and protofibrils, as well as fibrils, from various $A \beta$ peptide sequences. This method has been used extensively by our group and by many other researchers in the field to elucidate $A \beta$ amyloid formation, investigate the nature of the toxic $A \beta$ species and develop amyloid-based diagnostic tools and therapeutic strategies for AD. This paper provides a convenient reference for the $A D$ research community for reliable preparation and isolation of these different $A \beta$ aggregate states for structural and functional studies.

\section{Preparation and characterization of monomeric $A \beta$}

Fractionation. Lyophilized $A \beta$ peptides, obtained from different sources, are easily solubilized using 6-M guanidine hydrochloride, and the resultant solution contains predominantly monomeric $A \beta$ (Fig. 3). Insoluble preexisting aggregates, if present, are effectively removed with brief centrifugation $(\geq 16,000 \mathrm{~g}, \sim 10 \mathrm{~min})$. When this guanidine hydrochloride solution of $A \beta$ is injected into a Superdex 75 HR 10/30 SEC column, the peptide elutes as a single peak in the included volume of SEC column (0.45-0.55 CV for Superdex 75 HR 10/30; elution volume $11-13 \mathrm{ml}$ ) corresponding to predominantly monomeric $A \beta$ (Fig. 3a-red line). Generally, $1 \mathrm{mg}$ of $\mathrm{A} \beta 40$ or $\mathrm{A} \beta 42$ ( $80 \%$ net weight) dissolved in $1 \mathrm{ml}$ of guanidine hydrochloride yields $\sim 2 \mathrm{ml}$ at final concentrations of $\sim 50-80 \mu \mathrm{M}$. Previous translational diffusion measurements of these $A \beta$ elution fractions, by pulse field gradient solution phase NMR, showed that $A \beta$ predominantly elutes as a monomer ${ }^{80}$. The presence of a small amount of LMW oligomers (dimers, trimers, and so on), which exist in rapid equilibrium with the monomer, has been suggested and cannot be ruled out ${ }^{53,73}$. However, these oligomeric species do not seem to accumulate or exist in stable forms, unless stabilized by chemical crosslinking ${ }^{17}$.

Characterization. Reinjection of purified monomers into a Superdex 75 pc 3.2/30 SEC analytical column showed a single elution peak and confirmed that the fractions corresponded to monomeric (M) a
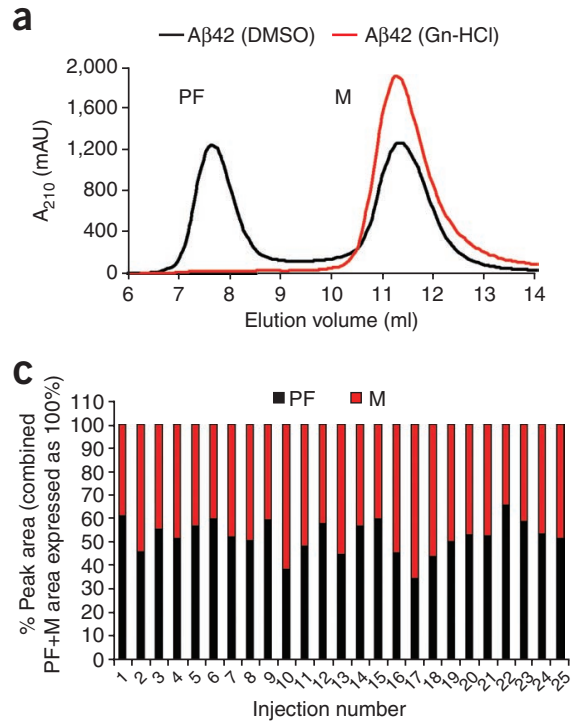

e

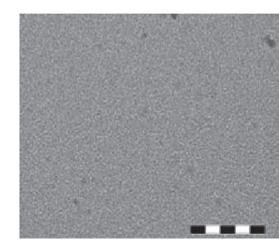

f

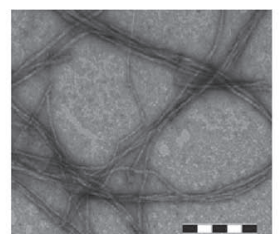

b
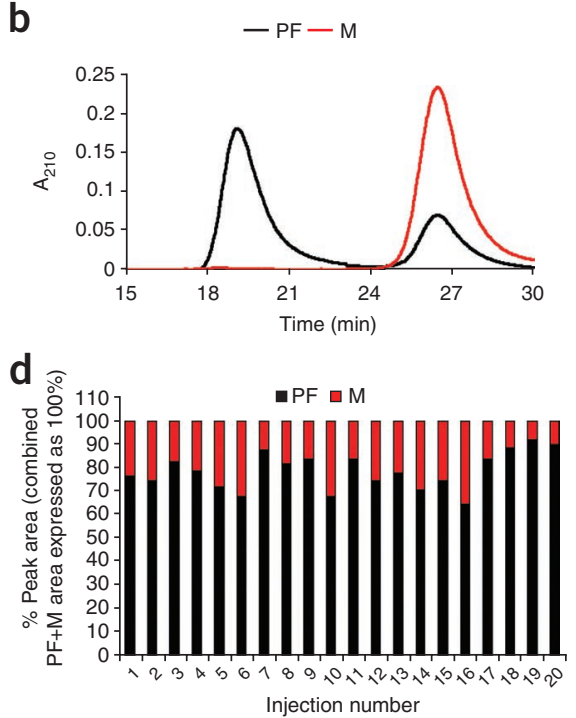

g

h

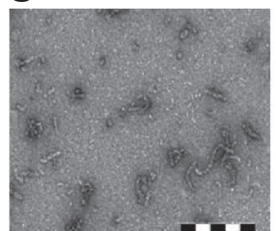

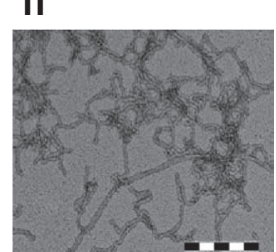

Figure 3 | SEC fractionation and biophysical characterization of A 342 monomers and protofibrils. (a) Fractionation of A 42 into protofibrillar (black line-using DMSO solubilization method) or monomeric (M) fractions (red line; using $6 \mathrm{M}$ guanidine hydrochloride solubilization method) on a Superdex $75 \mathrm{HR}$ 10/30 SEC column. (b) Analytical SEC (Ana-SEC) of protofibrillar (black line) and monomeric A 342 (red line; using $6 \mathrm{M}$ guanidine hydrochloride solubilization method) on a Superdex 75 pc 3.2/30 SEC column. (c) Statistical analysis of the mean peak area for the elution of protofibrils and monomeric A $\beta 42$ (using DMSO solubilization method) on a Superdex 75 HR 10/30 SEC column from previous 25 injections. For each injection, the total $(\mathrm{PF}+\mathrm{M})$ peak area was expressed as $100 \%(n=25 ; \mathrm{PF}: \mathrm{M}$ ratio $=52: 48 ; \%$ s.d. from the mean $=\operatorname{PF}(0.8-18)$ and $M(0.1-13))$. (d) Statistical analysis of the mean peak area for the elution of monomer from SEC purified protofibrils, after re-injection into a Superdex 75 pc 3.2/30 for Ana-SEC, from previous 20 injections. For each injection, the total (PF $+M)$ peak area was expressed as $100 \%$ $(n=20 ; \mathrm{PF}: \mathrm{M}$ ratio $=79: 21 ; \%$ s.d. from the mean $=\mathrm{PF}(0.95-14)$ and $\mathrm{M}(0.05-13)) .(\mathbf{e}, \mathbf{f})$ Representative TEM images of monomeric $A \beta 42$ fractions soon after SEC (e) and fibrils formed by monomeric $A \beta 42$ after $96 \mathrm{~h}$ of incubation at $37^{\circ} \mathrm{C}(10 \mu \mathrm{M} \mathrm{A} \beta 42$, without agitation) (f). (g,h) Representative TEM images of A $\beta 42$ protofibrils soon after SEC $(\mathbf{g})$ and fibrils formed by $A \beta 42$ protofibrils after $96 \mathrm{~h}$ of incubation at $37^{\circ} \mathrm{C}$

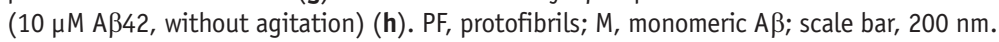


elution (Fig. $\mathbf{3 b}$ red line; peak around $\sim 26 \mathrm{~min}$ ). TEM analysis of monomeric fractions, soon after fractionation, confirmed the absence of any aggregated $A \beta$ in these preparations (Fig. $3 e$ ) (monomeric $A \beta$ is not detectable by TEM). Circular dichroism (CD) analysis followed by spectra deconvolution using CCA + software Lincomb algorithm ${ }^{81,82}$ was carried out to assess the secondary structure elements of the $A \beta$ fractions. $C D$ analysis of this preparation showed a spectrum with minima at $195-205 \mathrm{~nm}$, consistent with a predominantly random coil conformtion (Supplementary Fig. 1a). Deconvolution of the spectrum suggested a mixture of predominantly $(60 \%)$ random coil conformation and 39\% $\beta$-turn structure. SDS-PAGE and the subsequent silver staining and/or western immunoblotting with $6 \mathrm{E} 10$ antibody showed that SEC-isolated monomeric A $\beta 40$ migrated as a single band. In contrast, monomeric $A \beta 42$ fractions migrated as a mixture of monomers, dimers and trimers, with monomer being the predominant species under similar conditions of electrophoresis (Supplementary Fig. 1b). Previous studies have suggested that this anomalous migration of A 42 on SDS gels is a result of SDS-induced A $\beta$ oligomerization because of the effect of SDS micelle formation and high local concentration of $A \beta$ in micelles ${ }^{73}$. In addition, it is also possible that $A \beta 42$ at higher than critical concentrations, and because of its high aggregation tendency, exists in equilibrium with LMW oligomers (dimers, trimers and low $n$-mers) seen on the gels ${ }^{53,73}$.

Briefly, the SEC method outlined above ensures that the starting material of the experiment is predominantly monomeric $A \beta$, free of protofibrillar or fibrillar aggregates and can be obtained in solutions free of organic solvents and compatible with cell culture manipulations. The extent of oligomerization and the amount of LMW oligomers formed is strongly dependent on the $A \beta$ peptide sequence, the $A \beta$ concentration and the incubation temperature and time. Therefore, we recommend the immediate use of SEC fractions or the maintenance of samples at $4{ }^{\circ} \mathrm{C}$ until use. Although we have not observed significant protofibril formation by TEM and ThT binding, when these solutions are stored at $4^{\circ} \mathrm{C}$ for up to $24 \mathrm{~h}$ (Supplementary Fig. $3 \mathrm{c}, \mathbf{i}$ ), we cannot rule out that the oligomerization and formation of LMW oligomers take place under these conditions. This is especially critical when A 342 and $A \beta 42 / A \beta 40$-Arctic mutant (E22G) are used and stored at concentrations $>50 \mu \mathrm{M}$. Therefore, we recommend that peptide solutions be prepared freshly before performing the experiments, maintained at $4^{\circ} \mathrm{C}$ and used within a few hours $(<3-5 \mathrm{~h}$ ). If the experimental setup and conditions do not allow for rapid preparation and the immediate use of the monomeric $A \beta$ fractions, we recommend that the samples be stored at $4{ }^{\circ} \mathrm{C}$. To ensure the absence of fibrillar or protofibrillar aggregates at the time of using a stored sample, a small aliquot can be centrifuged and evaluated by Ana-SEC, ThT and TEM.

\section{Preparation and characterization of $A \beta 42$ protofibrils}

Fractionation. To generate protofibrils of $A \beta 42$, or $A \beta$ sequences with a high aggregation tendency (like $A \beta$-Arctic), the peptide is solubilized using the DMSO method ${ }^{18}$ (Step 1B). This method is very effective in yielding a solution enriched with protofibrils of broad size distribution ${ }^{18}$; however, this preparation also contains a significant amount of monomeric $A \beta$ that must be separated from the protofibrils. Fractionating this preparation on a Superdex 75 HR 10/30 SEC column yields two elution peaks separated by $\geq 2 \mathrm{ml}$ of elution volume. The first peak corresponding to the void volume ( 7-9 $\mathrm{ml}$ of elution volume for the HR 10/30 columns) is enriched with protofibrils (PF), whereas the second elution peak corresponds to monomeric (M) A 342 (Fig. 3a, black line). When $1 \mathrm{mg}$ of A 342 ( $\sim 80 \%$ net weight) is solubilized using the DMS0 method (860 $\mu$ l of total solution) and fractionated as mentioned, the typical yield is as follows: $\mathrm{PF} \sim 2 \mathrm{ml}, \sim 40-60 \mu \mathrm{M}$ of final $\mathrm{A} \beta$ concentration and $\mathrm{M} \sim 2 \mathrm{ml}, \sim 40-50 \mu \mathrm{M}$ of final $\mathrm{A} \beta$ concentration.

Reproducibility of fractionation. Generally, when A 42 is solubilized in DMSO and fractionated, the PF peak area and height are almost always greater than the M peak, but the absolute values are not identical from one injection to another. To illustrate this, analysis of A 42 protofibrillar preparations (using the DMSO method), carried out by three different individuals in our group over the past 2-3 years, is presented in Figure 3c. The data show that there is occasional variation between the extent of PF and M elution. For each injection, the combined (PF + M) peak area was expressed as $100 \%$. The percentage (\%) mean peak area for $\mathrm{PF}$ and $\mathrm{M}$ elution was calculated and the results confirmed that the usual trend of $\mathrm{A} \beta 42$ elution is $\mathrm{PF}>\mathrm{M}$ (the mean peak area ratio of $P F$ to $M=52: 48 ; \%$ s.d. from mean: $P F=0.8-18, M=0.1-13 ; n=25$ ). For $A \beta 40$ or other lessaggregation-prone $A \beta$ sequences, the $M$ elution almost always predominates (Supplementary Fig. 1f). Despite these slight variations, structural analysis of A $342 \mathrm{PF}$ and M fractions did not exhibit any drastic differences (data not shown). However, these different elution patterns produce variations in the concentration of $A \beta$ fractions.

Characterization. Protofibrils were obtained as described above and subjected to further analysis. TEM analysis of the protofibril fractions showed aggregates of various morphologies including curvilinear aggregates ( $<200 \mathrm{~nm}$ long) and small spherical structures (Fig. $\mathbf{3 g}$ ). These observations were consistent with previously described morphologies for protofibrils ${ }^{12,13}$. Protofibrils, on reinjection into an Ana-SEC (a Superdex 75 pc 3.2/30 column), elute predominantly in the void elution volume (Fig. 3b, black line; peak height around $19 \mathrm{~min}$ ). Interestingly, in addition to void volume elution, we consistently observe an additional small peak corresponding to the monomer elution. This could be due to either the reestablishment of monomer-protofibril equilibrium, monomer dissociation due to interactions with the chromatography matrix or a combination of both. To determine whether this monomer peak was consistent and also whether there was a variation in this peak from one protofibril preparation to another, we carried out statistical analysis of 20 Ana-SEC elution profiles of A 42 protofibrils. 
The analysis was based on reinjection of purified protofibrils on independent occasions and using different preparations. For each reinjection, the combined (PF + M) peak area was expressed as $100 \%$ and the percentage (\%) mean peak area for PF and $M$ elution was calculated. The data presented in Figure 3d show that SEC-purified protofibrils, when reinjected into a Superdex 75 pc 3.2/30 column, predominantly elute in the void volume, with a small elution peak corresponding to monomeric elution (mean peak area PF:M $=79: 21 ; \%$ s.d. from mean: $\mathrm{PF}=0.95-14, \mathrm{M}=0.05-13 ; n=20$ ).

The fractions were then subjected to $C D$ spectroscopy for analysis of secondary structure elements. CD spectra deconvolution, carried out using the CCA + software Lincomb algorithm ${ }^{81,82}$, showed that the protofibrils, obtained using this protocol, consisted of $43 \% \beta$-sheet, $38 \% \alpha$-helix and $5 \%$ random coil as secondary structure elements (Supplementary Fig. 1a). These values for the secondary structure elements were similar as reported previously for A 40 protofibrils and show that protofibrils consist of mixed $\alpha$-helical- $\beta$-sheet structural elements ${ }^{14,20}$.

Similar to protofibrils of synthetic A 340 (ref. 14), A 342 protofibrils are SDS-labile and run as multiple bands (monomer to trimer), along with a high-molecular-weight smear, by SDS-PAGE (Supplementary Fig. 1b), despite the fact that these species elute in the void volume of Superdex $75(>70 \mathrm{kDa})$, which should only contain PFs. This anomalous migration on SDS gels by protofibrils and oligomers of $s A \beta$ has also been reported by other groups ${ }^{13,83}$. There are different possibilities to explain these experimental observations; (i) some of these LMW oligomers may exist in rapid equilibrium with protofibrils;

(ii) these oligomers may not exist in solution but form as a result of SDS-induced disassociation of protofibrils; or

(iii) formation of these species may be induced by the interaction of A $\beta$ with SDS micelles as described above ${ }^{73}$.

SDS-stable $A \beta$ oligomers have been consistently observed in naturally secreted $A \beta$ preparations obtained from the conditioned media of Chinese hamster ovary cells, overexpressing wt APP or APP-bearing fAD mutations ${ }^{19,55}$. These species migrate predominantly as dimers and trimers on SDS-PAGE and have been proposed as bona fide oligomers ${ }^{19}$. However, these species are distinct from the oligomeric forms described above, because they were shown to be stable and did not disassociate after treatment with formic acid, heating or incubation with chemical denaturants (guanidine hydrochloride). Furthermore, naturally secreted oligomers have not been shown to undergo further oligomerization and fibril formation. Although chemical modifications and/or covalent cross-linking of monomeric $A \beta$ species could explain the kinetic stability and lack of fibrillization by these oligomers, direct evidence for such modifications by mass spectrometry or by other tools remains lacking.

\section{Fibrillization studies}

To study the aggregation and kinetics of fibril formation, purified A 42 PF and M fractions were separately incubated $(\sim 10 \mu \mathrm{M})$ at $37^{\circ} \mathrm{C}$ without agitation and allowed to fibrillize. Consistent with previous reports ${ }^{13}$, we observed that PF fractions showed a less pronounced rise in ThT binding over time, compared with M fractions (Supplementary Fig. 1c). TEM analysis, after $96 \mathrm{~h}$ of incubation, revealed that although in the case of monomeric fraction elongated intertwining fibrils were formed (Fig. 3f), the PF fraction contained a substantial amount of elongated protofibrils interspersed among fibrils (Fig. $3 \mathrm{~h}$ ). The slow fibrillization of protofibrils is consistent with the proposed mechanism of fibril formation by monomer addition, rather than annealing and/or self-assembly of protofibrillar aggregates ${ }^{20,21}$. Indeed, addition of monomeric $A \beta$ to protofibrillar fractions accelerates their fibrillization ${ }^{21}$.

\section{Preparation and characterization of $A \beta 40$ protofibrils}

$\mathrm{A} \beta 40$ protofibrils can be generated in a consistent manner by dissolving the peptide in $\mathrm{NaOH}$ and rapidly moving the highly acidic TFA salt peptide through its isoelectric point to a pH of 7.2-7.6 (ref. 14). Incubating the peptide at $500 \mu \mathrm{M}$ in PBS (pH 7.4) for 2-3 d at RT generates monomers and protofibrils, which vary around a PF:M ratio in the range of 40-60\% (ref. 14). The progression of protofibril formation can be quantitatively monitored on a daily basis by injecting small aliquots of the stock solution into a Superdex 75 HR 10/30 SEC column or into an analytical Superdex 75 pc 3.2/30 column. Before injecting into an SEC column, the sample is briefly centrifuged $\left(16,000 \mathrm{~g}\right.$ for $10 \mathrm{~min}$ at $\left.4^{\circ} \mathrm{C}\right)$ to remove any fibrils that might have formed during the incubation. This is usually indicated by the appearance of a pellet after the centrifugation. TEM analysis of the pellet obtained in this procedure revealed that they are predominately made of fibrils ${ }^{14}$. Regarding the SEC elution profile, the protofibril peak appears first in the void volume ( 7-9 $\mathrm{ml}$ for HR 10/30 columns) and can be collected in 0.5-1-mL fractions with $A \beta$ concentrations ranging from 10 to $40 \mu \mathrm{M}$. TEM images of this protofibril peak showed small spheres, 4-6 $\mathrm{nm}$ in diameter with a variation in length, and curvilinear structures $<200 \mathrm{~nm}$ in length and 4-6 nm in width ${ }^{14}$. The CD spectrum of these fractions showed a broad negative ellipticity between 225 and $208 \mathrm{~nm}$, consistent with the presence of a mixture of random coil, $\alpha$-helix and $\beta$-sheet structures ${ }^{14}$. Estimation of the secondary structure contents of the CD spectra, performed using the CDANAL program ${ }^{82}$ and the Brahms and Brahms reference library ${ }^{84}$, showed that these protofibril preparations contain $47 \% \beta$-sheet, $40 \%$ random coil and $13 \% \alpha$-helix secondary structure elements ${ }^{20}$. In addition, the protofibril peak was found to bind Congo red and ThT similarly, but to a lesser extent, than mature fibrils ${ }^{14,20}$. The protofibril fractions can be combined $(\sim 1-2 \mathrm{ml})$ or analyzed separately depending on the concentration of peptide and solution volume needed. The monomer peak emerges in the included volume, as mentioned above, and can yield similar concentrations as the protofibril peak. TEM analysis of monomer fractions confirmed the aggregate-free nature 
of the preparation ${ }^{14,20}$. SDS-PAGE, followed by western blotting analysis, for monomer fractions, showed a single $4-\mathrm{kDa}$ band; however, the protofibrillar fractions migrated as a mixture of multiple bands with molecular weights corresponding to species from monomer to tetramer ${ }^{14}$. The latter observation suggested that $A \beta 40$ protofibrils were not SDS stable and migrated as LMW bands on SDS gels.

\section{Application to $A \beta$ fAD mutants}

The methods described above for wt $A \beta$ ( $A \beta 40$ and $A \beta 42)$ solubilization and fractionation are also useful for preparation of different monomeric and protofibril fractions of fAD $A \beta$ mutants. We have used this protocol to isolate the monomeric and protofibrillar forms of AB40-Arctic (E22G), A $340-$ Dutch (E22Q) and Aß40-Flemish (A21G) peptides. Figure 4 summarizes the results of these studies. A $\beta 40-$ Arctic (E22G) exhibits faster aggregation kinetics than does wt $A \beta 40$ and has a higher tendency to form and accumulate protofibrils ${ }^{18,36,85}$. Accordingly, we found that dissolving synthetic A 340 -Arctic in DMSO (Step 1B) resulted in a solution that is highly enriched with protofibrils and monomeric $A \beta$. Fractionation of this solution on a Superdex 75 HR 10/30 column showed that the predominant elution peak was in the void volume (Fig. 4a, black line) and contained aggregates of heterogeneous morphologies including curvilinear and spherical assemblies (Fig. 4e). The fibrillization studies revealed that A 340 -Arctic formed high ThT-binding fibrils, both from solution containing monomeric or protofibrillar A $\beta 40$-Arctic (Figs. $\mathbf{2 h}$ and $\mathbf{4 b}$, only fibrils from the monomeric fraction are shown). Using the DMS0 solubilization method, the yield of $A \beta 40$-Arctic is similar to that of $A \beta 42$ protofibrils (2 $\mathrm{ml}$; $\sim 40-60 \mu \mathrm{M})$. Previous efforts to generate A 340 -Arctic protofibrils, using the $\mathrm{NaOH}$ solubilization method, resulted in only 10-40 $\mu \mathrm{M}$ for similar volumes ${ }^{18}$. Therefore, we recommend using the DMSO solubilization method (Step 1B) for generating A $\beta 40$-Arctic protofibrils. The A $\beta 40$-Dutch (E22Q) mutant exhibited a similar SEC elution pattern as the wt $A \beta 42$

(Fig. 4a, red line); however, these protofibrils formed fibrils only at concentrations $\geq 20 \mu \mathrm{M}$ (Figs. $2 \mathbf{i}$ and $4 \mathrm{c}$ ). Finally, Aß40-Flemish (A21G) also eluted as two peaks corresponding to a protofibrillar and monomeric species (Fig. 4a, green line), but neither was shown to form fibrils over the time course of the experiment ( $96 \mathrm{~h}$ incubation at $37^{\circ} \mathrm{C}$, without agitation) (Figs. $2 \mathbf{j}$ and $\mathbf{4 d}$ ). These observations are in accordance with previously published reports showing that Arctic (E22G) and Dutch (E22Q) mutations in A $\beta$ significantly increase fibril nucleation and growth, whereas the Flemish $(\mathrm{A} 21 \mathrm{G})$ mutation decreases fibril growth ${ }^{85}$.

\section{Application to rA $\beta$ peptides and synthetic peptides from other sources}

Next, we sought to determine whether this protocol for generation of monomeric and protofibrillar $A \beta$ fractions is equally applicable to synthetic $(s A \beta)$ and recombinant forms (rAB) of $A \beta$ obtained from different sources. For this purpose, we obtained synthetic A 342 (as TFA salt) from Bachem (Switzerland, cat. no. H-1368). rA $\beta$ peptides were purchased from a commercial source (rPeptides, Bogart, GA, USA) and were also donated generously by two independent research groups (Carl Frieden, Washington University, St. Louis, USA and Rudolf Glockshuber, ETH, Zurich, Switzerland). Further, the rAß42 peptides from rPeptides were provided as either TFA (cat. no. A-1002-2) or $\mathrm{NaOH}$ (cat. no. A-1165-2) salts, thus allowing us to determine whether different counterions affect the extent of protofibril formation. All $s A \beta$ and $r A \beta$ peptides were solubilized using the DMSO method and fractionated on a Superdex 75 HR 10/30 column. Synthetic and recombinant A 42 eluted as protofibrillar and monomer peaks (Fig. 5a,b), and TEM analysis of the protofibrillar fractions showed predominantly curvilinear and spherical morphologies (Fig. 5c-f).
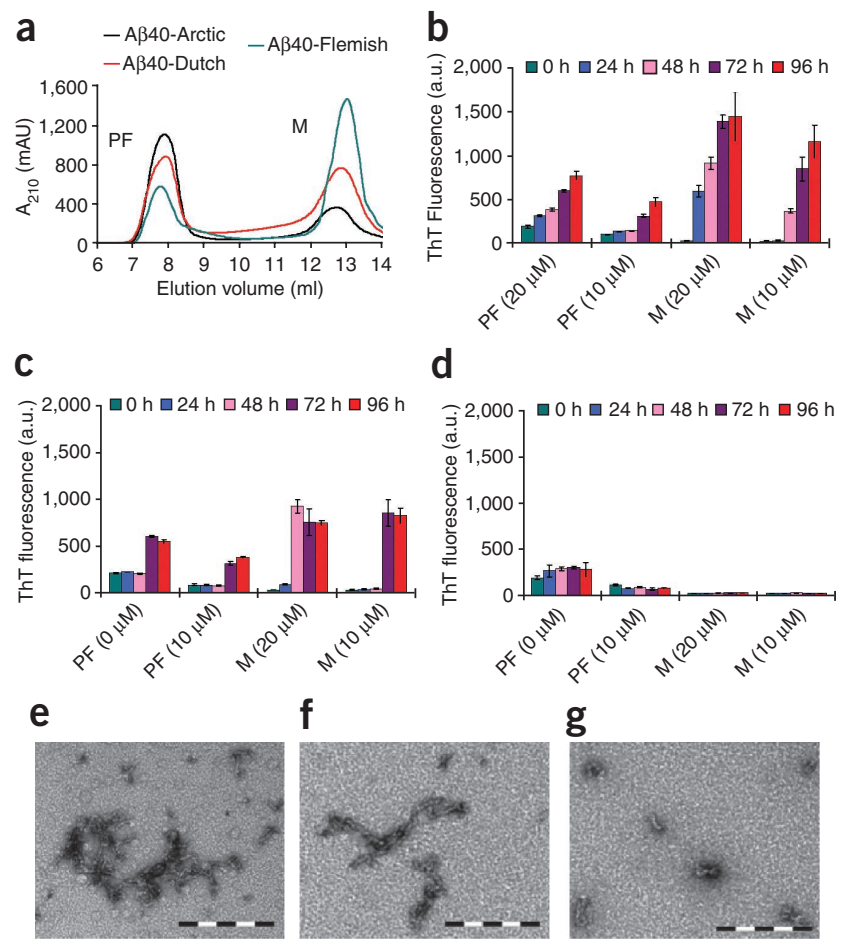

g

Figure 4 | Application to $A A D$-associated $A \beta$ mutant peptides. (a) SEC fractionation of DMSO solubilized A $\beta 40$-Arctic (black line), A 340 -Dutch (red ine) and A 340 -Flemish (green line) on a Superdex 75 HR 10/30 column. Dutch (c) and A 340 -Flemish (d) assessed by ThT binding assay (10 $\mu$ M A ; $96 \mathrm{~h}, 37{ }^{\circ} \mathrm{C}$ without agitation). (e-j) TEM analysis of SEC isolated protofibrils of fibrils or non-fibril A340-Dutch (i) and AB40-Flemish (j) after $96 \mathrm{~h}$ incubation $\left(10 \mu \mathrm{M} \mathrm{A \beta}, 37^{\circ} \mathrm{C}\right.$ without agitation). $P F$, protofibrils; $M$, monomeric $A \beta$; a.u., arbitrary units; the error bars in (b-d) represent s.d. in duplicate samples; scale bar, $200 \mathrm{~nm}$. 
Recombinant $A \beta 40$ peptides also eluted in an identical manner as synthetic $A \beta 40$ (Keck facility), as a predominant single elution peak in the included volume and as a small peak in the void volume (Supplementary Fig. $1 \mathbf{f}-\mathbf{g}$ ). These observations show that the protocol outlined above is applicable to $A \beta$ peptides from synthetic and recombinant sources. However, it is noteworthy that protofibrils are a heterogeneous population of aggregates and it is quite likely that the size distribution among protofibrils might not be identical for $A \beta$ prepared in different methods (synthetic and recombinant).

\section{Subfractionation of $A \beta 42$ protofibrils and aggregated $A \beta 42$} Further separation of protofibrils of different sizes can be achieved using columns with different separation capacities or combining multiple columns with extended separation ranges (Table 2) (for example, the Superose 6 HR 10/30 column by itself (Supplementary Fig. 2) or a Superose 6 HR 10/30 column connected in series to a TSK-GEL 4,000 SEC column). Generally, this procedure yields from four to six protofibril fractions ( $1 \mathrm{ml}$ each), but only the first and last fractions differ significantly in terms of size and morphology distribution. For example, we previously showed that fractionation of the protofibril peak, obtained from a $1: 1$ solution mixture of $A \beta$-Arctic and $A \beta 40$ wt, using a Superose 6 column, yielded seven protofibril fractions ${ }^{18}$. Only fraction 7 was highly enriched in annular $A \beta$ structures, with a molecular weight distribution centered around $150-250 \mathrm{kDa}$. The remaining fractions were heterogeneous and exhibited a molecular weight distribution of 80-880 $\mathrm{kDa}^{18}$. We have observed that the addition of monomers of a slow aggregating sequence (e.g., $A \beta 40$ ) to a highly amyloidogenic sequence (e.g., $A \beta 42$ (ref. 21) and $A \beta 40-$ Arctic ${ }^{18}$ ) results in kinetic stabilization of the protofibrils formed by the more amyloidogenic sequence. This strategy can be exploited to stabilize protofibrils and facilitate their purification ${ }^{18}$.

\section{Stability of the preparation}

Considering the situations in which fractionation is not immediately possible, or when protofibrils are not used within a day after fractionation or samples need to be sent to another location, we sought to determine the stability of the protofibrillar preparation over time. To study this, we solubilized synthetic A $342\left(1 \mathrm{mg} \mathrm{ml}^{-1}\right.$, using the DMSO method) and either injected $\left(250 \mu \mathrm{l}\right.$ ) into a Superdex 75 column immediately after solubilization (and centrifugation) or left the solution at $4^{\circ} \mathrm{C}$ for a duration of up to $24 \mathrm{~h}$. At 4 and $24 \mathrm{~h}$, the solution was centrifuged and injected $(250 \mu \mathrm{l})$. We observed that the protofibrillar peak area increased by $\sim 10-15 \%$, as compared with time 0 , with a corresponding decline in the monomer peak area

(Supplementary Fig. 3a). A TEM analysis of the crude (CR) stock solution after $4 \mathrm{~h}$ of incubation at $4^{\circ} \mathrm{C}$ revealed predominantly protofibrillar structures and did not show any fibrils (Supplementary Fig. 3d,g). Although the peptide loss due to fibril formation, if any, was minimal, we do not recommend storage of the stock solution for more than $2-4 \mathrm{~h}$.

Similarly, SEC-isolated protofibril fractions $(1 \mathrm{ml}, \sim 50 \mu \mathrm{M})$ were also incubated at $4{ }^{\circ} \mathrm{C}$ for $24 \mathrm{~h}$. Comparison of sample reinjection, soon after fractionation and after $24 \mathrm{~h}$ of incubation at $4{ }^{\circ} \mathrm{C}$, showed that the predominant elution was in the void volume (\% total peak area: PF $=80-86, \mathrm{M}=14-20$ ) (Supplementary Fig. 3b). TEM analysis, after $24 \mathrm{~h}$ of incubation at $4{ }^{\circ} \mathrm{C}$, did not show any mature fibrils; however, protofibrils seemed to cluster with extended incubation (Supplementary Fig. 3e,h).

\section{Preparation of $\mathbf{A} \boldsymbol{\beta}$ fibrils}

The majority of structural and toxicity studies have compared the properties of monomeric and protofibrillar $A \beta$ with that of $A \beta$ fibrils. $A \beta$ fibrils can be generated using purified monomeric preparations or $C R A \beta$ preparations, i.e., those that contain a mixture of monomeric and protofibrillar species, depending on the quantity of fibrils desired and the experimental conditions used. Both methods yield fibrils of similar ThT binding and morphologies.

For highly aggregation-prone sequences (e.g., $A \beta 42$ wt or $A \beta 40$-Arctic), fibrils can be obtained by incubating monomeric $A \beta$ $(10-50 \mu \mathrm{M})$ at $37^{\circ} \mathrm{C}$ under mild agitation for 24-48 h (Figs. 3f and $\mathbf{4 h}$, respectively, for A $342 \mathrm{WT}$ or $A \beta 40$-Arctic). A $\beta 40$ fibril 
formation, from SEC-isolated monomeric $\mathrm{A} \beta 40$, requires concentrations $\geq 50 \mu \mathrm{M}$ and agitation for 24-48 $\mathrm{h}^{21}$. These conditions result in the formation of mature amyloid fibrils with an average diameter of 8-12 $\mathrm{nm}$. The fibrils are characterized by high ThT binding and TEM analysis, and shows an extensive network of intertwining $>1-\mu \mathrm{m}$-long filamentous morphologies.

Fibrils can also be prepared from high concentrations of $C R A \beta$ preparations (1-2 $\mathrm{mg} \mathrm{ml}^{-1}$ of $A \beta$ solutions containing monomers, protofibrils and a small amount of fibrils) obtained using one of the methods described for generating protofibrils (the DMSO or $\mathrm{NaOH}$ method). Concentrated stock solutions are incubated at $37^{\circ} \mathrm{C}$, under mild agitation, for $24 \mathrm{~h}$. This method generates high ThT-binding fibrils with morphologies similar to those obtained when using purified monomeric $A \beta$ (Supplementary Fig. 1d,e). Preparing fibrils from CR mixtures allows for obtaining fibrils in a short time span and for the generation of large quantities of fibrils for use in high-throughput screening or in vivo studies. Therefore, we recommend the latter method only if experiments demand substantial quantities of fibrils.

\section{SEC-isolated $A \boldsymbol{\beta}$ fractions are toxic to cultured neurons}

Initial studies showing the neurotoxic nature of protofibrils used $A \beta 40$ protofibrils isolated by SEC using a Sephadex G75 column ${ }^{14,20}$. Applications of $\sim 20 \mu \mathrm{M}$ protofibrils produced massive cell loss over a $5 \mathrm{~d}$ period, as measured by LDH (Fig. 6a) ${ }^{14}$. This was a

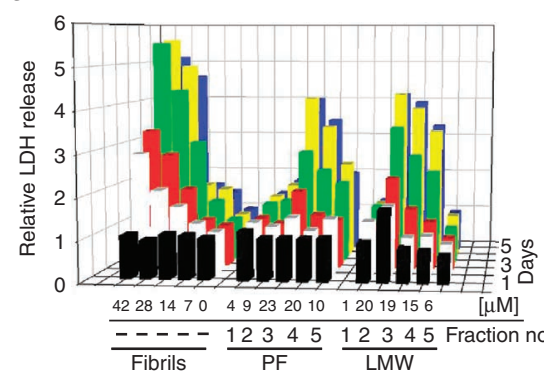

C

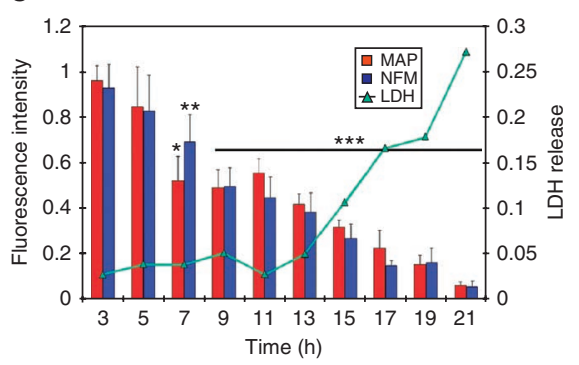

b

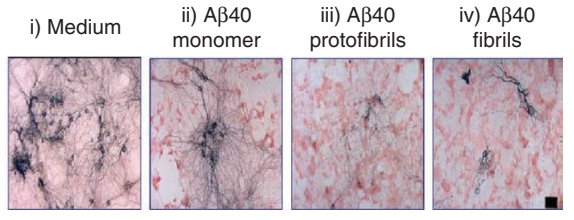

d

$\begin{array}{lll}\text { i) } A \beta 40-A r c t i c & \text { ii) } A \beta 40-\text { Arctic } & \text { iii) } A \beta 40-\text { Arctic }\end{array}$ monomer $(0 \mathrm{~h}) \quad$ monomer $(10 \mathrm{~h}) \quad$ monomer $(24 \mathrm{~h})$
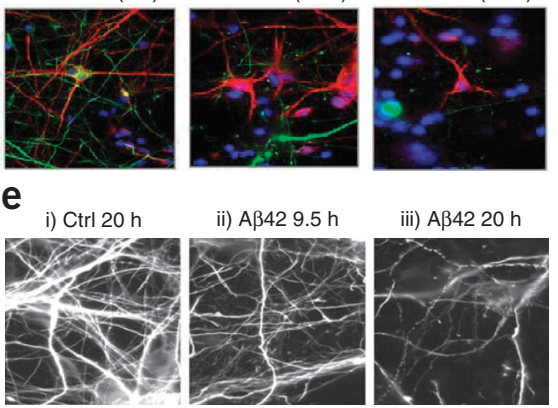

Figure 6 | Neurotoxicity of SEC-purified $A \beta$ monomers and protofibrils. (a,b) Time course of wild-type A $\beta 40$-induced injury: $A \beta 40$ was incubated at $500 \mu \mathrm{M}$ in PBS for $3 \mathrm{~d}$ at RT, and then centrifuged to remove fibrils. The monomeric and protofibril fractions were isolated by SEC using a Superdex 75 10/30 column. The monomeric (LMW) and protofibril (PF) peaks were collected in 0.5-ml fractions to which modified neurobasal medium was added, and then placed on primary cerebral cortical cultures. (a) Neuronal loss was measured by LDH release into the culture medium every $24 \mathrm{~h}$. Each monomeric and protofibril peak was collected in 5 individual fractions and $A \beta$ concentration was measured in each. Control LDH release (no $A \beta$ added) is listed as " 0 " under fibrils and given a value of 1 . (b) Neurons were exposed to medium only (i), monomeric $A \beta(18 \mu \mathrm{M})$ (ii), protofibrils (21 $\mu \mathrm{M})$ (iii), or fibrils $(20 \mu \mathrm{M}$ for $5 \mathrm{~d}$ ) (iv), and then cultures were preserved and stained with microtubule associated protein-2 (MAP2) to identify neurons (dark blue staining). (c,d) Time course of A $\beta 40$-Arctic-induced injury: A $\beta 40$-Arctic was solubilized using $6 \mathrm{M}$ guanidine hydrochloride and fractionated on a Superdex 75 10/30 column. Modified neurobasal medium was added to the monomeric fractions ( $A \beta$ diluted to $20-\mu M$ concentration). (c) Quantitative results of the immunocytochemical staining and biochemical measurements of LDH release. Statistically significant loss of neuronal process is observed by $7 \mathrm{~h}$, whereas the release of LDH was not significant until 15 h. Data is reproduced with copyright approval ${ }^{65}$. (d) Immunocytochemical staining of primary cerebral cortical neurons treated with monomeric $A \beta 40$-Arctic at time 0 (i), show a progressive neurodegeneration with initial loss of dendrites by MAP2 staining (red) and axons by NF-M staining (green) at $10 \mathrm{~h}$ (ii) followed by cell loss at $24 \mathrm{~h}$ (iii). (e) Time course of A $\beta 42$-induced injury: $A \beta 42$ was solubilized using $6 \mathrm{M}$ guanidine $\mathrm{HCl}$ solubilization method and fractionated on a Superdex G75 10/30 column. Modified Neurobasal media was added to the monomeric fractions. Neurons, on coverslips, were treated with A $\beta 42(22.5 \mu \mathrm{M})$. At 9.5- and 20-h time periods, coverslips were removed, fixed and stained for Neurofilament N, an axon-specific protein. (i) Healthy neurons receiving no A $\beta 42$ for $20 \mathrm{~h}$; (ii) Neurons losing neuronal process as early as $9.5 \mathrm{~h}$; (iii) Further neuronal loss observed at $20 \mathrm{~h}$. The time course of neurite loss with $A \beta 42$ was very similar to the findings with $A \beta 40$-Arctic in $d$.

supported by cytological observations showing loss of neuronal processes and cell bodies (Fig. $\mathbf{6 b})^{14}$. A concern with cell culture experiments is that the aggregation state of $A \beta$ can change with extended incubation periods (>2-6 $h$ ), depending on the concentration of the peptide. Cell culture media were collected after $5 \mathrm{~d}$ and no fibrils could be observed in either the monomer or protofibril-treated cultures ${ }^{14}$. This suggested that fibrils were not killing the neurons and some $A \beta$ species preceding fibril formation were toxic. Interestingly, similar neuronal death was observed with monomeric fractions after 10-24 h of treatment as the protofibril preparation (Fig. 6a) ${ }^{14}$, suggesting that monomer fractions can form nonfibrillar $A \beta$ aggregates during the course of the experiment, which might have contributed and/or caused toxicity. Instantaneous readout such as the MTT assay or electrophysiology has confirmed that protofibrils have their own inherent biological activity ${ }^{14,20}$. In support of the soluble $A \beta$ aggregates causing neurotoxicity, preparations of disaggregated A $\beta 40$-Arctic peptide purified by SEC were found to produce rapid toxicity ${ }^{65}$. A 340 -Arctic induced neuronal loss, but observations at earlier time points (within $5 \mathrm{~h}$ ) showed morphological changes in neuronal dendrites and axons, which preceded the rise in LDH (Fig. 6c) ${ }^{65}$. Similarly, isolating monomeric $A \beta 42$ and applying it to primary neocortical cultures produced a loss of neuronal process (Fig. 6e) that was almost identical to that of $A \beta 40$-Arctic (Fig. $\mathbf{6 d}$ ). These findings support the concept that prefibrillar aggregates of $A \beta$ induce synaptic failure, which precedes overt cell loss. These data show the value and versatility of SEC to generate different $A \beta$ preparations in order to probe the pathophysiological relevance of various aggregation states in $A D$. 
Note: Supplementary information is available via the HTML version of this article.

ACKNOWLEDGMENTS This work was supported by the Swiss Federal Institute of Technology Lausanne (EPFL) and by grants from the Swiss National Foundation (Grant \# 310000-110027), the National Institute on Aging, USA (Grant \# AG19970) (D.M.H.) and from the Alzheimer's Association (D.M.H.). We thank AC Immune (S.A.), Lausanne, Switzerland for financially supporting Asad Jan. We also thank Professor Andrea Pfeifer, Dr. Andreas Muhs and Dr. Oskar Adolfsson from AC Immune (S.A.), Lausanne, Switzerland for thoughtful discussions. We also thank Professor Carl Frieden, Washington University, St. Louis, USA and Professor Rudolf Glockshuber, ETH, Zurich, Switzerland for kindly providing recombinant $A \beta$ peptides. We gratefully acknowledge Dr. Graham Knott at Bio-Electron Microscopy Facility (CIME), EPFL, Lausanne for technical support with TEM; Dr. Harald Wutzel, Laboratory of Polymers, EPFL, Lausanne for help with dynamic light-scattering measurements; and Dr. Michel Prudent, LMNN, EPFL, Lausanne for help with mass spectrometry measurements.

AUTHOR CONTRIBUTIONS A.J. and H.A.L. contributed to the fractionation data and biophysical characterization of SEC fractions. D.M.H. provided the A $\beta$ toxicity data and protocols for preparing and treating neuronal cultures in modified neurobasal media for toxicity studies. A.J., D.M.H. and H.A.L. contributed to writing the paper.

COMPETING FINANCIAL INTERESTS The authors declare no competing financial interests.

Published online at http://www.natureprotocols.com/.

Reprints and permissions information is available online at http://npg.nature.com/ reprintsandpermissions/.

1. Hebert, L.E., Scherr, P.A., Bienias, J.L., Bennett, D.A. \& Evans, D.A. Alzheimer disease in the US population: prevalence estimates using the 2000 census. Arch. Neurol. 60, 1119-1122 (2003).

2. Selkoe, D.J. Alzheimer's disease: genes, proteins, and therapy. Physiol. Rev. 81, 741-766 (2001).

3. Glenner, G.G., Wong, C.W., Quaranta, V. \& Eanes, E.D. The amyloid deposits in Alzheimer's disease: their nature and pathogenesis. Appl. Pathol. 2, 357-369 (1984).

4. Haass, C. et al. Amyloid beta-peptide is produced by cultured cells during normal metabolism. Nature 359, 322-325 (1992).

5. Busciglio, J., Gabuzda, D.H., Matsudaira, P. \& Yankner, B.A. Generation of beta-amyloid in the secretory pathway in neuronal and nonneuronal cells. Proc. Natl. Acad. Sci. USA 90, 2092-2096 (1993).

6. Shoji, M. et al. Production of the Alzheimer amyloid beta protein by normal proteolytic processing. Science 258, 126-129 (1992).

7. Hardy, J.A. \& Higgins, G.A. Alzheimer's disease: the amyloid cascade hypothesis. Science 256, 184-185 (1992).

8. Selkoe, D.J. Alzheimer's disease: a central role for amyloid. J. Neuropathol. Exp. Neurol. 53, 438-447 (1994).

9. Jarrett, J.T. \& Lansbury, P.T., Jr. Seeding 'one-dimensional crystallization' of amyloid: a pathogenic mechanism in Alzheimer's disease and scrapie? Cell 73, 1055-1058 (1993).

10. Kelly, J.W. The alternative conformations of amyloidogenic proteins and their multi-step assembly pathways. Curr. Opin. Struct. Biol. 8, 101-106 (1998).

11. Harper, J.D., Lieber, C.M. \& Lansbury, P.T., Jr. Atomic force microscopic imaging of seeded fibril formation and fibril branching by the Alzheimer's disease amyloid-beta protein. Chem. Biol. 4, 951-959 (1997).

12. Harper, J.D., Wong, S.S., Lieber, C.M. \& Lansbury, P.T. Observation of metastable Abeta amyloid protofibrils by atomic force microscopy. Chem. Biol. 4, 119-125 (1997).

13. Walsh, D.M., Lomakin, A., Benedek, G.B., Condron, M.M. \& Teplow, D.B. Amyloid beta-protein fibrillogenesis. Detection of a protofibrillar intermediate. J. Biol. Chem. 272, 22364-22372 (1997).

14. Hartley, D.M. et al. Protofibrillar intermediates of amyloid beta-protein induce acute electrophysiological changes and progressive neurotoxicity in cortical neurons. J. Neurosci. 19, 8876-8884 (1999).

15. Lambert, M.P. et al. Diffusible, nonfibrillar ligands derived from Abeta1-42 are potent central nervous system neurotoxins. Proc. Natl. Acad. Sci. USA 95, 6448-6453 (1998)

16. Kayed, R. et al. Annular protofibrils are a structurally and functionally distinct type of amyloid oligomer. J. Biol. Chem. 284, 4230-4237 (2009).

17. Bitan, G. et al. Amyloid beta -protein (Abeta) assembly: Abeta 40 and Abeta 42 oligomerize through distinct pathways. Proc. Natl. Acad. Sci. USA 100, 330-335 (2003).
18. Lashuel, H.A. et al. Mixtures of wild-type and a pathogenic (E22G) form of Abeta40 in vitro accumulate protofibrils, including amyloid pores. J. Mol. Biol. 332, 795-808 (2003).

19. Walsh, D.M. et al. Naturally secreted oligomers of amyloid beta protein potently inhibit hippocampal long-term potentiation in vivo. Nature 416, 535-539 (2002).

20. Walsh, D.M. et al. Amyloid beta-protein fibrillogenesis. Structure and biological activity of protofibrillar intermediates. J. Biol. Chem. 274, 25945-25952 (1999).

21. Jan, A., Gokce, O., Luthi-Carter, R. \& Lashuel, H.A. The ratio of monomeric to aggregated forms of Abeta 40 and Abeta42 is an important determinant of amyloid-beta aggregation, fibrillogenesis, and toxicity. J. Biol. Chem. 283, 28176-28189 (2008).

22. Williams, A.D. et al. Structural properties of Abeta protofibrils stabilized by a small molecule. Proc. Natl. Acad. Sci. USA 102, 7115-7120 (2005).

23. Kheterpal, I. et al. Abeta protofibrils possess a stable core structure resistant to hydrogen exchange. Biochemistry 42, 14092-14098 (2003).

24. Stine, W.B., Jr. et al. The nanometer-scale structure of amyloid-beta visualized by atomic force microscopy. J. Protein Chem. 15, 193-203 (1996).

25. Serpell, L.C. Alzheimer's amyloid fibrils: structure and assembly. Biochim Biophys Acta 1502, 16-30 (2000).

26. Narang, H.K. High-resolution electron microscopic analysis of the amyloid fibril in Alzheimer's disease. J. Neuropathol. Exp. Neurol. 39, 621-631 (1980).

27. Merz, P.A. et al. Ultrastructural morphology of amyloid fibrils from neuritic and amyloid plaques. Acta Neuropathol 60, 113-124 (1983).

28. Gong, Y. et al. Alzheimer's disease-affected brain: presence of oligomeric A beta ligands (ADDLs) suggests a molecular basis for reversible memory loss. Proc. Natl. Acad. Sci. US A 100, 10417-10422 (2003).

29. Lemere, C.A. et al. Sequence of deposition of heterogeneous amyloid betapeptides and APO E in Down syndrome: implications for initial events in amyloid plaque formation. Neurobiol. Dis. 3, 16-32 (1996).

30. Irizarry, M.C. et al. Abeta deposition is associated with neuropil changes, but not with overt neuronal loss in the human amyloid precursor protein V717F (PDAPP) transgenic mouse. J. Neurosci. 17, 7053-7059 (1997).

31. McLean, C.A. et al. Soluble pool of Abeta amyloid as a determinant of severity of neurodegeneration in Alzheimer's disease. Ann. Neurol. 46, 860-866 (1999).

32. Wang, J., Dickson, D.W., Trojanowski, J.Q. \& Lee, V.M. The levels of soluble versus insoluble brain Abeta distinguish Alzheimer's disease from normal and pathologic aging. Exp. Neurol. 158, 328-337 (1999).

33. Citron, M. et al. Mutation of the beta-amyloid precursor protein in familial Alzheimer's disease increases beta-protein production. Nature 360, 672-674 (1992).

34. Eckman, C.B. et al. A new pathogenic mutation in the APP gene (I716V) increases the relative proportion of A beta 42(43). Hum. Mol. Genet. 6, 2087-2089 (1997).

35. Goate, A. et al. Segregation of a missense mutation in the amyloid precursor protein gene with familial Alzheimer's disease. Nature 349, 704-706 (1991).

36. Nilsberth, C. et al. The 'Arctic' APP mutation (E693G) causes Alzheimer's disease by enhanced Abeta protofibril formation. Nat. Neurosci. 4, 887-893 (2001).

37. Holcomb, L. et al. Accelerated Alzheimer-type phenotype in transgenic mice carrying both mutant amyloid precursor protein and presenilin 1 transgenes. Nat. Med. 4, 97-100 (1998).

38. Moechars, D. et al. Early phenotypic changes in transgenic mice that overexpress different mutants of amyloid precursor protein in brain. J. Biol. Chem. 274, 6483-6492 (1999).

39. Meyer-Luehmann, M. et al. Exogenous induction of cerebral betaamyloidogenesis is governed by agent and host. Science 313, 1781-1784 (2006).

40. Ye, C.P., Selkoe, D.J. \& Hartley, D.M. Protofibrils of amyloid beta-protein inhibit specific K+ currents in neocortical cultures. Neurobiol. Dis. 13, 177-190 (2003).

41. Ye, C., Walsh, D.M., Selkoe, D.J. \& Hartley, D.M. Amyloid beta-protein induced electrophysiological changes are dependent on aggregation state: $\mathrm{N}$-methyl-D-aspartate (NMDA) versus non-NMDA receptor/channel activation. Neurosci. Lett. 366, 320-325 (2004).

42. Wang, Q., Walsh, D.M., Rowan, M.J., Selkoe, D.J. \& Anwyl, R. Block of long-term potentiation by naturally secreted and synthetic amyloid betapeptide in hippocampal slices is mediated via activation of the kinases c-Jun $\mathrm{N}$-terminal kinase, cyclin-dependent kinase 5, and p38 mitogenactivated protein kinase as well as metabotropic glutamate receptor type 5. J. Neurosci. 24, 3370-3378 (2004). 
43. Lambert, M.P. et al. Vaccination with soluble Abeta oligomers generates toxicity-neutralizing antibodies. J. Neurochem. 79, 595-605 (2001).

44. Dodart, J.C. et al. Immunization reverses memory deficits without reducing brain Abeta burden in Alzheimer's disease model. Nat. Neurosci. 5, 452-457 (2002)

45. Lashuel, H.A., Hartley, D., Petre, B.M., Walz, T. \& Lansbury, P.T., Jr. Neurodegenerative disease: amyloid pores from pathogenic mutations. Nature 418, 291 (2002).

46. Arispe, N., Rojas, E. \& Pollard, H.B. Alzheimer disease amyloid beta protein forms calcium channels in bilayer membranes: blockade by tromethamine and aluminum. Proc. Natl. Acad. Sci. USA 90, 567-571 (1993).

47. Kayed, R. et al. Permeabilization of lipid bilayers is a common conformation-dependent activity of soluble amyloid oligomers in protein misfolding diseases. J. Biol. Chem. 279, 46363-46366 (2004).

48. Li, S. et al. Soluble oligomers of amyloid Beta protein facilitate hippocampal long-term depression by disrupting neuronal glutamate uptake. Neuron 62, 788-801 (2009).

49. Deshpande, A., Mina, E., Glabe, C. \& Busciglio, J. Different conformations of amyloid beta induce neurotoxicity by distinct mechanisms in human cortical neurons. J. Neurosci. 26, 6011-6018 (2006).

50. Klein, A.M., Kowall, N.W. \& Ferrante, R.J. Neurotoxicity and oxidative damage of beta amyloid 1-42 versus beta amyloid 1-40 in the mouse cerebral cortex. Ann. N Y Acad. Sci. 893, 314-320 (1999).

51. Roselli, F. et al. Soluble beta-amyloid1-40 induces NMDA-dependent degradation of postsynaptic density-95 at glutamatergic synapses. J. Neurosci. 25, 11061-11070 (2005).

52. Zagorski, M.G. et al. Methodological and chemical factors affecting amyloid beta peptide amyloidogenicity. Methods Enzymol. 309, 189-204 (1999).

53. Bitan, G. \& Teplow, D.B. Preparation of aggregate-free, low molecular weight amyloid-beta for assembly and toxicity assays. Methods Mol. Biol. 299, 3-9 (2005).

54. Ward, R.v. et al. Fractionation and characterization of oligomeric, protofibrillar and fibrillar forms of beta-amyloid peptide. Biochem. J. 348 (Pt 1): 137-144 (2000).

55. Klyubin, I. et al. Amyloid beta protein immunotherapy neutralizes Abeta oligomers that disrupt synaptic plasticity in vivo. Nat. Med. 11, 556-561 (2005).

56. Roher, A.E. et al. Morphology and toxicity of Abeta-(1-42) dimer derived from neuritic and vascular amyloid deposits of Alzheimer's disease. J. Biol. Chem. 271, 20631-20635 (1996).

57. Snyder, S.W. et al. Amyloid-beta aggregation: selective inhibition of aggregation in mixtures of amyloid with different chain lengths. Biophys. J. 67, 1216-1228 (1994).

58. Herzig, M.C. et al. Abeta is targeted to the vasculature in a mouse model of hereditary cerebral hemorrhage with amyloidosis. Nat. Neurosci. 7, 954-960 (2004).

59. Younkin, S.G. Evidence that A beta 42 is the real culprit in Alzheimer's disease. Ann. Neurol. 37, 287-288 (1995).

60. Zou, K. et al. Amyloid beta-protein (Abeta)1-40 protects neurons from damage induced by Abeta1-42 in culture and in rat brain. J. Neurochem. 87, 609-619 (2003).

61. Arimon, M., Grimminger, V., Sanz, F. \& Lashuel, H.A. Hsp104 targets multiple intermediates on the amyloid pathway and suppresses the seeding capacity of Abeta fibrils and protofibrils. J. Mol. Biol. 384, 1157-1173 (2008).

62. Pike, C.J., Burdick, D., Walencewicz, A.J., Glabe, C.G. \& Cotman, C.W. Neurodegeneration induced by beta-amyloid peptides in vitro: the role of peptide assembly state. J. Neurosci. 13, 1676-1687 (1993).

63. Lorenzo, A. \& Yankner, B.A. Beta-amyloid neurotoxicity requires fibril formation and is inhibited by congo red. Proc. Natl. Acad. Sci. USA 91, 12243-12247 (1994).

64. Seilheimer, B. et al. The toxicity of the Alzheimer's beta-amyloid peptide correlates with a distinct fiber morphology. J. Struct. Biol. 119, 59-71 (1997).

65. Whalen, B.M., Selkoe, D.J. \& Hartley, D.M. Small non-fibrillar assemblies of amyloid beta-protein bearing the Arctic mutation induce rapid neuritic degeneration. Neurobiol. Dis. 20, 254-266 (2005).

66. Wogulis, M. et al. Nucleation-dependent polymerization is an essential component of amyloid-mediated neuronal cell death. J. Neurosci. 25, 1071-1080 (2005).

67. Chromy, B.A. et al. Self-assembly of Abeta(1-42) into globular neurotoxins. Biochemistry 42, 12749-12760 (2003).
68. Walsh, D.M., Klyubin, I., Fadeeva, J.V., Rowan, M.J. \& Selkoe, D.J. Amyloid-beta oligomers: their production, toxicity and therapeutic inhibition. Biochem. Soc. Trans. 30, 552-557 (2002).

69. Cleary, J.P. et al. Natural oligomers of the amyloid-beta protein specifically disrupt cognitive function. Nat. Neurosci. 8, 79-84 (2005).

70. Lesne, S. et al. A specific amyloid-beta protein assembly in the brain impairs memory. Nature 440, 352-357 (2006).

71. Kayed, R. et al. Common structure of soluble amyloid oligomers implies common mechanism of pathogenesis. Science 300, 486-489 (2003).

72. Lambert, M.P. et al. Monoclonal antibodies that target pathological assemblies of Abeta. J. Neurochem. 100, 23-35 (2007).

73. Bitan, G., Fradinger, E.A., Spring, S.M. \& Teplow, D.B. Neurotoxic protein oligomers--what you see is not always what you get. Amyloid 12, 88-95 (2005).

74. May, P.C. et al. Beta-Amyloid peptide in vitro toxicity: lot-to-lot variability. Neurobiol. Aging 13, 605-607 (1992).

75. Walsh, D.M. et al. A facile method for expression and purification of the Alzheimer's disease-associated amyloid beta-peptide. FEBS J. 276, 1266-1281 (2009).

76. Finder, V.H., Vodopivec, I., Nitsch, R.M. \& Glockshuber, R. The recombinant amyloid-beta peptide Abeta1-42 aggregates faster and is more neurotoxic than synthetic Abeta1-42. J. Mol. Biol. 396, 9-18.

77. Garai, K., Crick, S.L., Mustafi, S.M. \& Frieden, C. Expression and purification of amyloid-beta peptides from Escherichia coli. Protein Expr. Purif. 66, 107-112 (2009).

78. Sato, T. et al. Inhibitors of amyloid toxicity based on beta-sheet packing of Abeta40 and Abeta42. Biochemistry 45, 5503-5516 (2006).

79. Brewer, G.J., Torricelli, J.R., Evege, E.K. \& Price, P.J. Optimized survival of hippocampal neurons in B27-supplemented Neurobasal, a new serum-free medium combination. J. Neurosci. Res. 35, 567-576 (1993).

80. Tseng, B.P. et al. Deposition of monomeric, not oligomeric, Abeta mediates growth of Alzheimer's disease amyloid plaques in human brain preparations. Biochemistry 38, 10424-10431 (1999).

81. Perczel, A., Hollosi, M., Tusnady, G. \& Fasman, G.D. Convex constraint analysis: a natural deconvolution of circular dichroism curves of proteins. Protein Eng. 4, 669-679 (1991).

82. Perczel, A., Park, K. \& Fasman, G.D. Analysis of the circular dichroism spectrum of proteins using the convex constraint algorithm: a practical guide. Anal. Biochem. 203, 83-93 (1992).

83. Hepler, R.W. et al. Solution state characterization of amyloid beta-derived diffusible ligands. Biochemistry 45, 15157-15167 (2006).

84. Brahms, S. \& Brahms, J. Determination of protein secondary structure in solution by vacuum ultraviolet circular dichroism. J. Mol. Biol. 138, 149-178 (1980).

85. Betts, V. et al. Aggregation and catabolism of disease-associated intraAbeta mutations: reduced proteolysis of AbetaA21G by neprilysin. Neurobiol. Dis. 31, 442-450 (2008).

86. Pace, C.N., Vajdos, F., Fee, L., Grimsley, G. \& Gray, T. How to measure and predict the molar absorption coefficient of a protein. Protein Sci. 4, 2411-2423 (1995).

87. Westermark, P. et al. Amyloid: toward terminology clarification. Report from the Nomenclature Committee of the International Society of Amyloidosis. Amyloid 12, 1-4 (2005).

88. Dobson, C.M. The structural basis of protein folding and its links with human disease. Philos. Trans. R. Soc. Lond. 356, 133-145 (2001).

89. Roher, A.E. et al. Oligomerizaiton and fibril asssembly of the amyloid-beta protein. Biochim. Biophys. Acta. 1502, 31-43 (2000).

90. Petkova, A.T. et al. Self-propagating, molecular-level polymorphism in Alzheimer's beta-amyloid fibrils. Science 307, 262-265 (2005).

91. Inouye, H., Fraser, P.E. \& Kirschner, D.A. Structure of beta-crystallite assemblies formed by Alzheimer beta-amyloid protein analogues: analysis by x-ray diffraction. Biophys. J. 64, 502-519 (1993).

92. Chamberlain, A.K. et al. Ultrastructural organization of amyloid fibrils by atomic force microscopy. Biophys. J. 79, 3282-3293 (2000).

93. Hoshi, M. et al. Spherical aggregates of beta-amyloid (amylospheroid) show high neurotoxicity and activate tau protein kinase I/glycogen synthase kinase-3beta. Proc. Natl. Acad. Sci. USA 100, 6370-6375 (2003).

94. Bitan, G., Lomakin, A. \& Teplow, D.B. Amyloid beta-protein oligomerization: prenucleation interactions revealed by photo-induced cross-linking of unmodified proteins. J. Biol. Chem. 276, 35176-35184 (2001).

95. O'Nuallain, B., Williams, A.D., Westermark, P. \& Wetzel, R. Seeding specificity in amyloid growth induced by heterologous fibrils. J. Biol. Chem. 279, 17490-17499 (2004). 

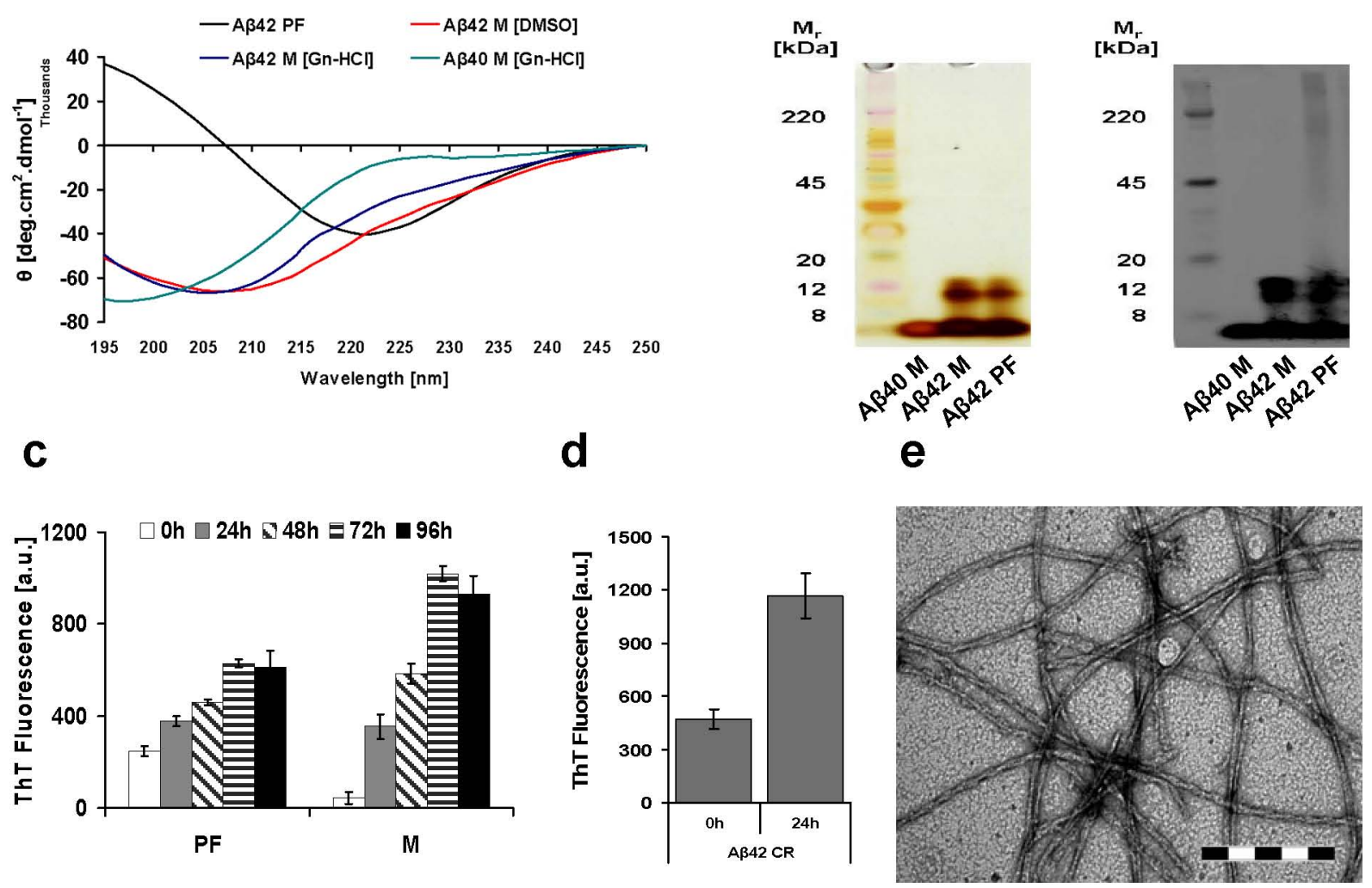

f

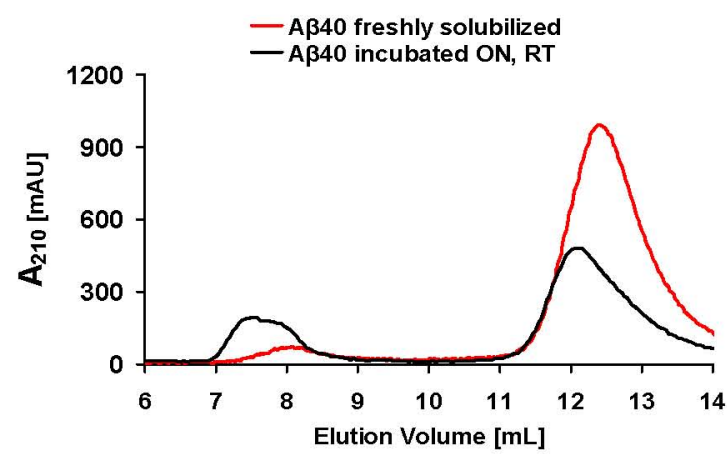

g

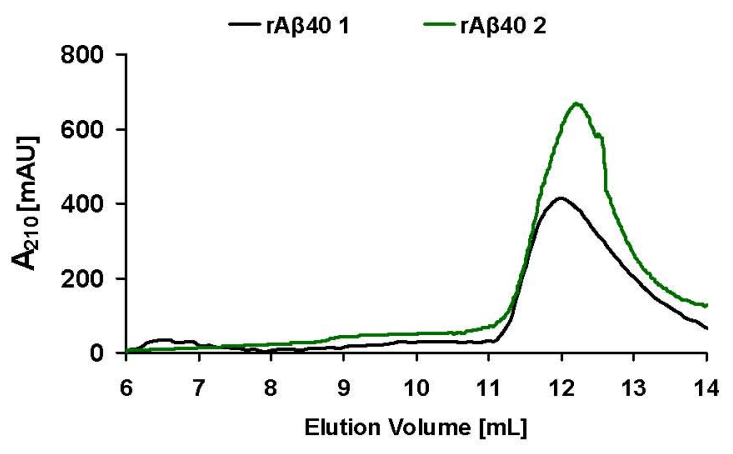

Supplementary Figure 1 (a) Circular dichroism (CD) spectroscopy analysis of SEC fractions from Superdex 75 HR 10/30 (AB40 and $A \beta 42)$ in a Jasco-810 CD Spectrometer using a $10 \mathrm{~mm}$ pathlength cell (black line $=A \beta 42$ protofibrils; red line $=A \beta 42$ monomer obtained using DMSO method; blue line $=A \beta 42$ monomer obtained using the $6 \mathrm{M}$ guanidine $-\mathrm{HCl}$ method; green line $=\mathrm{A} \beta 40$ monomer obtained using the $6 \mathrm{M}$ guanidine- $\mathrm{HCl}$ method). (b) $A \beta 40$ $($ monomeric $=M$ ) and $A \beta 42$ (monomeric $=M$ and protofibrillar $=P F)$ SEC fractions were obtained from a Superdex 75 HR 10/30 column and were electrophoresed on NuPAGE 4-12\% Bis Tris gels (Invitrogen, cat. No. NP0336BOX). The proteins were detected by (left) silver staining (SilverXpress, Invitrogen Cat. No. LC6100) and also, after having been transferred on a Nitrocellulose membrane (Whatman, Cat. No. 10401396), immunoblotting with anti-A $\beta$ antibody $6 \mathrm{E} 10$ (Signet, Cat. No. 9320). (c) Thioflavin-T (ThT) binding over time by protofibrillar and monomeric $A \beta 42$ fractions (10 $\mu \mathrm{M} \mathrm{A} \beta 42 ; 96 \mathrm{~h}, 37^{\circ} \mathrm{C}$ without agitation). (d-e) Fibril formation by $A \beta 42$ crude (stock solution obtained after DMSO solubilization method): SAß42 was solubilized using DMSO (1 mg ml-1) and incubated at $37^{\circ} \mathrm{C}$ with gentle agitation $(4,000 \mathrm{rpm})(\mathrm{d}) \mathrm{ThT}$ binding and (e) representative TEM image of resultant fibrils after $24 \mathrm{~h}$ of incubation. (f) SEC fractionation of synthetic AB40 (Keck facility), solubilized using DMSO method $\left(1 \mathrm{mg} \mathrm{ml}^{-1}\right)$, on a Superdex $75 \mathrm{HR} 10 / 30 \mathrm{SEC}$ column into protofibrils and monomeric $A \beta$ fractions. A 40 was solubilized and fractionated, without incubation (red line), or fractionated after incubation at room temperature, overnight (black line). (g) SEC fractionation of recombinant $\mathrm{rA \beta 40}$ from independent research groups, solubilized using DMSO method (0.5-1 mg ml-1), on a Superdex 75 HR 10/30 SEC. rAß40 1 (black line; $0.5 \mathrm{mg} \mathrm{ml}^{-1}$ ) was a generous gift from Prof. Rudolf Glockshuber, ETH, Zurich, Switzerland and $\mathrm{rA \beta 40} 2$ (green line; $1 \mathrm{mg} \mathrm{ml}^{-1}$ ) was generously provided by Prof. Carl Frieden, Washington University, St. Louis, USA. (Abbreviations: ON = Overnight; $R T=$ Room temperature; $P F=A \beta$ Protofibrils; $M=$ Monomeric $A \beta ; C R=$ Crude $A \beta 42 ;$ a.u. = arbitrary units; the error bars in ( $C$ and d) represent STD in duplicate samples; scale bar= $200 \mathrm{~nm}$ ). 
a

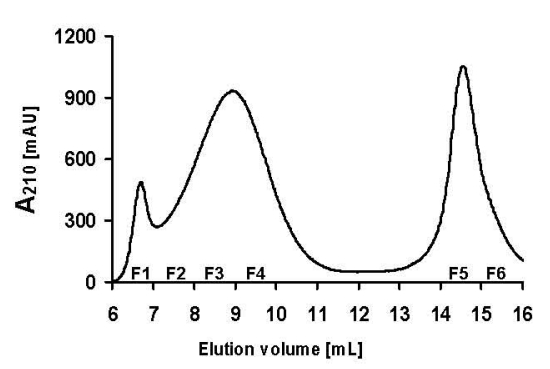

d

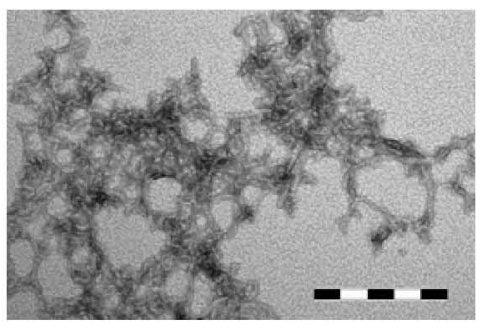

b

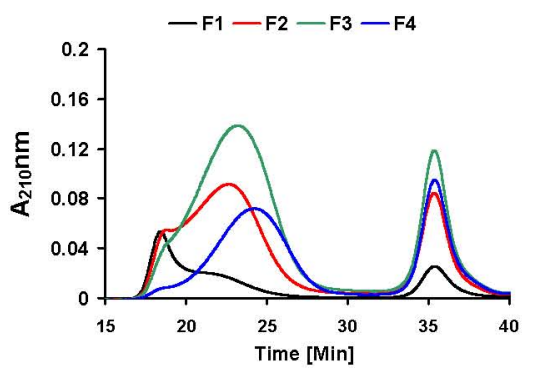

e

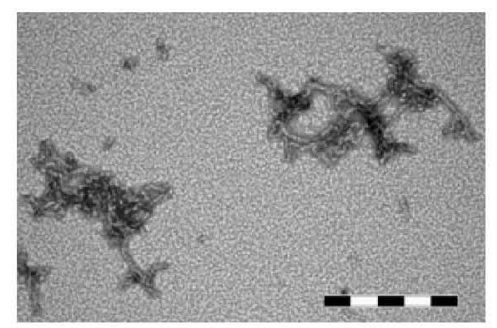

C

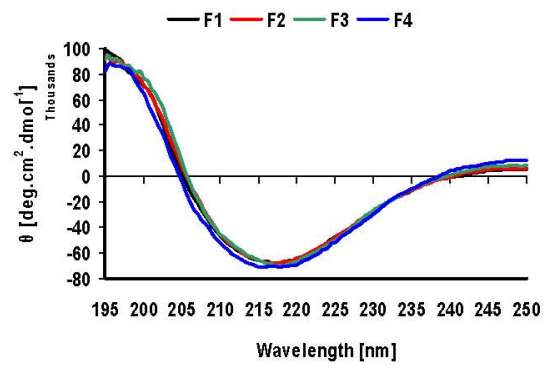

$\mathbf{f}$

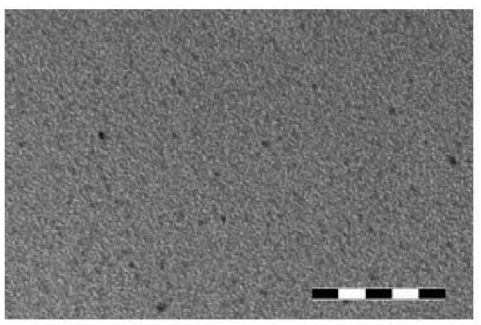

Supplementary Figure 2 | SEC sub-fractionation of $A \beta 42$ protofibrils on a Superose 6 HR 10/30 SEC column. (a) A 342 was solubilized using DMSO method ( $\left.2 \mathrm{mg} \mathrm{ml}^{-1}\right)$ and fractionated into protofibrillar (F1-F4) and monomeric (F5-F6) fractions on a Superose 6 HR 10/30 SEC column. (b) Analytical SEC of F1-F4 on Superose 6 pc 3.2/30 SEC column. (c) CD spectroscopy analysis of A $\beta$ 42 protofibrillar fractions from Superose 6 HR 10/30 as in Supplementary Figure 1a. (d-f) Representative TEM images of (d) F1, (e) F3 and (f) F5. (Abbreviations: F= Fraction; scale bar= $200 \mathrm{~nm}$ ). 

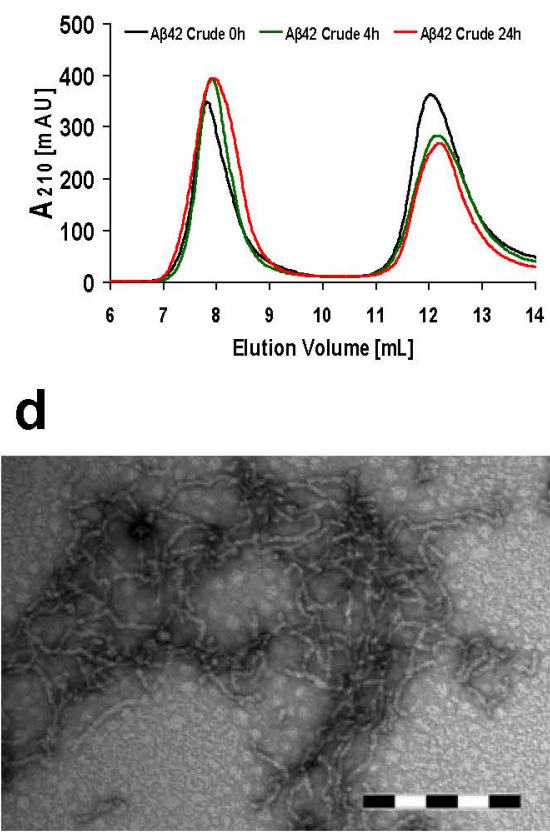

g

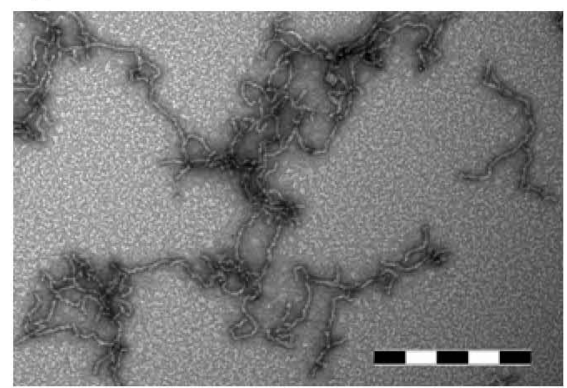

b

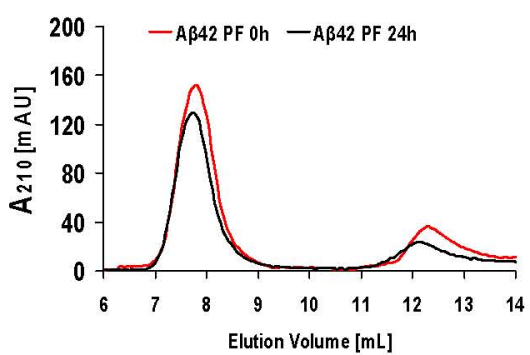

e

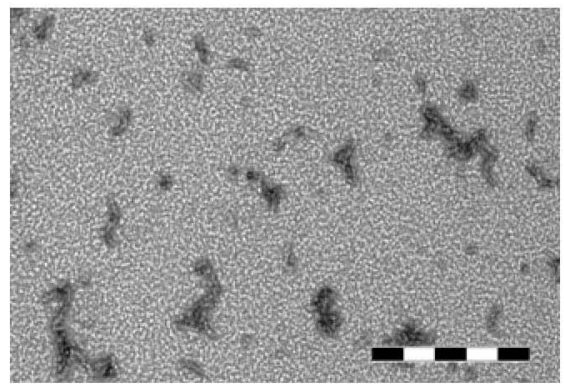

h

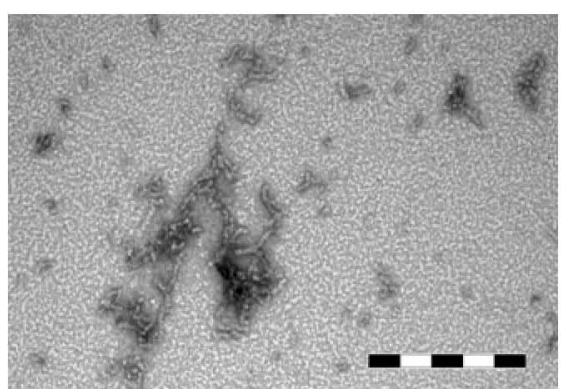

C

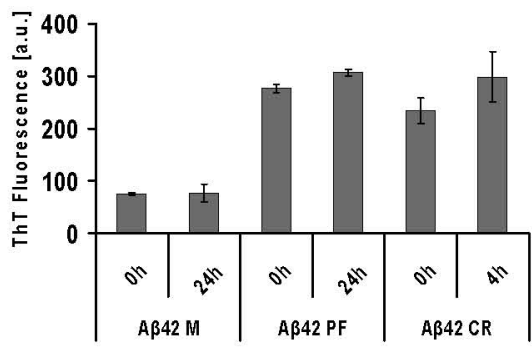

f

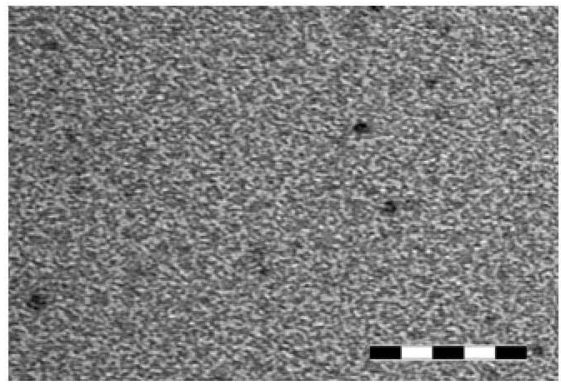

i

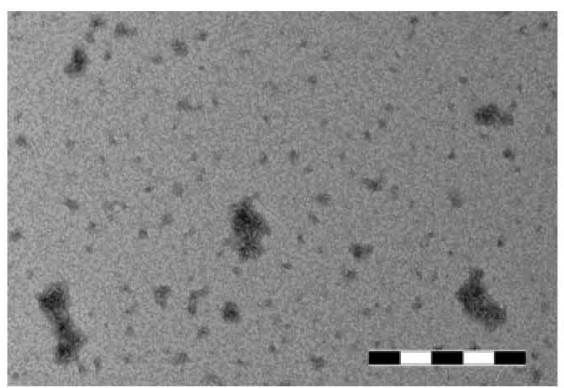

Supplementary Figure 3 I Stability of crude A 342 solution and SEC isolated protofibrillar and monomeric Aß42 fractions. (a) A 42 was solubilized (DMSO method, $\left.1 \mathrm{mg} \mathrm{ml}^{-1}\right)$ and split into three aliquots $(\sim 300 \mu$ I/aliquot). The first aliquot was injected immediately into a Superdex 75 HR 10/30 column. The second and third aliquots were incubated at $4^{\circ} \mathrm{C}$ for 4 and $24 \mathrm{~h}$ respectively, and then injected. At each time point, the solution was centrifuged $\left(16,000 \mathrm{~g}, 4^{\circ} \mathrm{C}, 10 \mathrm{~min}\right)$ and $250 \mu \mathrm{l}$ of the supernatant were injected. (b) Aß42 protofibrils were obtained by SEC and the fraction $(50 \mu \mathrm{M}, 1 \mathrm{ml})$ was split in two aliquots $(500 \mu \mathrm{l} /$ aliquot). The first aliquot was re-injected immediately into a Superdex $75 \mathrm{HR} 10 / 30$ column. The second aliquot was incubated at $4^{\circ} \mathrm{C}$ for $24 \mathrm{~h}$ then re-injected as above. At each time point, the solution was centrifuged $\left(16,000 \mathrm{~g}, 4^{\circ} \mathrm{C}, 10 \mathrm{~min}\right)$ and $400 \mu \mathrm{l}$ of supernatant were injected. (c) ThT binding by crude, protofibrillar and monomeric $A \beta 42$ after incubation at $4^{\circ} \mathrm{C}$. (d-i) Representative TEM images: (d and g) A 342 crude soon after solubilization and after $4 \mathrm{~h}$ of incubation at $4^{\circ} \mathrm{C}$, (e and $\mathrm{h}$ ) $\mathrm{A} \beta 42$ protofibrils soon after fractionation and after $24 \mathrm{~h}$ of incubation at $4^{\circ} \mathrm{C}$ and (f and $\mathrm{i}$ ) monomeric $\mathrm{A} \beta$ 42 soon after fractionation and after $24 \mathrm{~h}$ of incubation at $4^{\circ} \mathrm{C}$. (Abbreviations: $P F=A \beta 42$ Protofibrils; $M=M o n o-$ meric $A \beta 42 ; C R=$ Crude $A \beta 42$; a.u. = arbitrary units; the error bars in (c) represent STD in duplicate samples; scale bar= $200 \mathrm{~nm}$ ). 
a

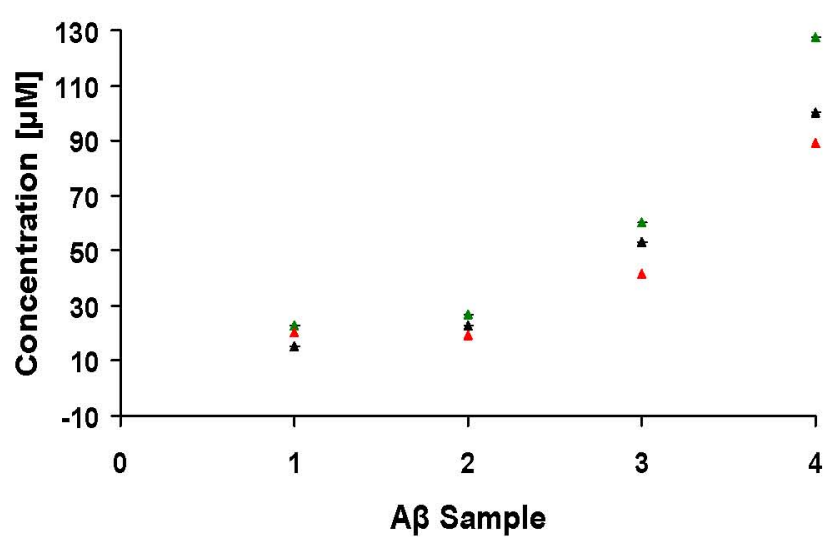

b

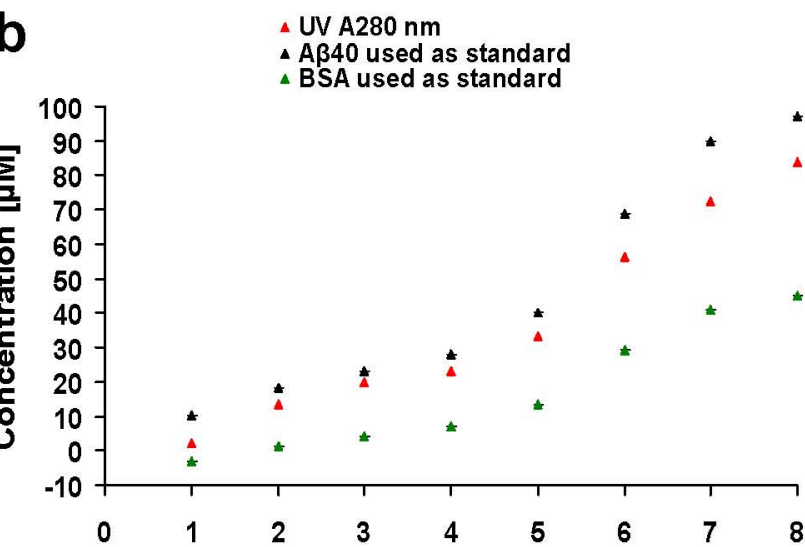

$A \beta$ Sample

C

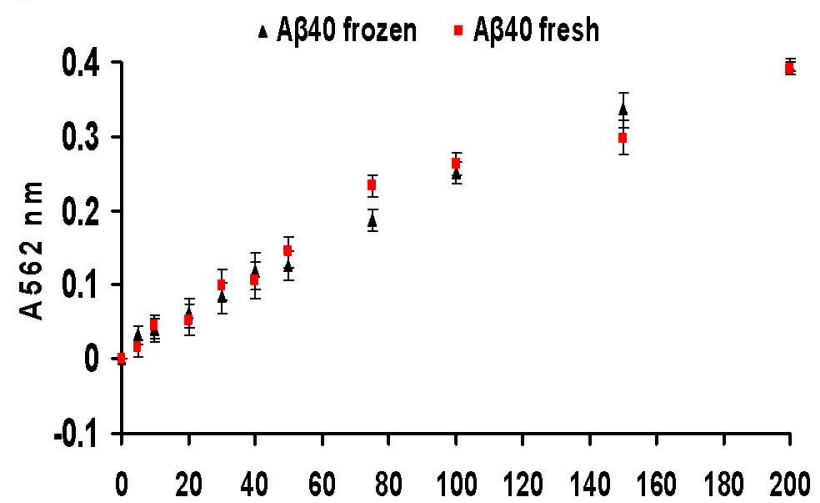

Aß40 [HM]
Supplementary Figure 4 I Comparative analysis of $A \beta$ concentration determination by amino acid analysis (AAA), BCA method and UV $A_{280}$ $\mathrm{nm}$ method. (a) The protein concentration of four $A \beta$ samples, from different fractionation experiments, was determined by AAA, BCA kit (Pierce Cat. No. 23227) and UV $A_{280} \mathrm{~nm}$ methods. AAA was carried out in FGCZ, ETH, Zurich, Switzerland. $A \beta$ standard curve, obtained from serial dilutions of $A \beta 40$ in $\mathrm{H}_{2} \mathrm{O}$, was used for $\mathrm{BCA}$. UV $\mathrm{A}_{280} \mathrm{~nm}$ for different fractions was determined in a $10 \mathrm{~mm}$ pathlength cuvette using a Cary spectrophotometer. (b) Protein concentration of eight $A \beta$ samples, from different fractionation experiments, was determined by BCA kit and UV $A_{280} \mathrm{~nm}$ methods. $A \beta$ concentration by BCA method was determined using a standard curve generated from both $A \beta 40$ and bovine serum albumin (BSA) serial dilutions. UV $A_{280} \mathrm{~nm}$ was carried out as in (a) above. BSA was provided as part of the PIERCE BCA kit. (c) Generation of standard curve of $A \beta 40$ for $B C A$ assay. $A \beta 40$ was freshly solubilized in double distilled $\mathrm{H}_{2} \mathrm{O}(1 \mathrm{mg}$ $\mathrm{ml}^{-1} ; 200 \mu \mathrm{M}$ by net weight; $80 \%$ peptide content) and serial dilutions $(5-200 \mu \mathrm{M})$ were prepared (in $\mathrm{H}_{2} \mathrm{O}$ ) for generating a standard curve for BCA assay. The stock $(200 \mu \mathrm{M}) \mathrm{A} \beta 40$ solution was aliquoted into sterile tubes (Fisherbrand, Cat. No. 05-669-27; $200 \mu \mathrm{l} /$ tube) and frozen at $-20^{\circ} \mathrm{C}$. After $24 \mathrm{~h}$ of freezing, one of the aliquots was thawn on ice, and serial dilutions (5-200 $\mu \mathrm{M})$ were carried out in $\mathrm{H}_{2} \mathrm{O}$. Protein concentration for both series of dilutions was determined by the BCA kit. Synthetic $A$ $\beta$ (Keck facility) was used for all measurements outlined in (a-c). 